\title{
European association for endoscopic surgery (EAES) consensus statement on single-incision endoscopic surgery
}

\author{
Salvador Morales-Conde ${ }^{1} \cdot$ Andrea Peeters $^{2} \cdot$ Yannick M. Meyer ${ }^{3}$ - Stavros A. Antoniou ${ }^{4} \cdot$ Isaías Alarcón del Agua ${ }^{1}$. \\ Alberto Arezzo ${ }^{5}$. Simone Arolfo ${ }^{5}$. Amir Ben Yehuda ${ }^{6}$. Luigi Boni ${ }^{7}$. Elisa Cassinotti ${ }^{7}$. Giovanni Dapri ${ }^{8} \cdot$ Tao Yang $^{1}$. \\ Sofie Fransen ${ }^{9}$. Antonello Forgione ${ }^{10}$. Shahab Hajibandeh ${ }^{11}$. Shahin Hajibandeh ${ }^{12}$. Michele Mazzola ${ }^{10}$. \\ Marco Migliore $^{5} \cdot$ Christof Mittermair $^{13} \cdot$ Doris Mittermair $^{13} \cdot$ Antonio Morandeira-Rivas $^{14} \cdot$ Carlos Moreno-Sanz $^{14}$. \\ Andrea Morlacchi ${ }^{15} \cdot$ Eran Nizri $^{16} \cdot$ Myrthe Nuijts $^{3}$. Jonas Raakow ${ }^{17}$. Francisco M. Sánchez-Margallo ${ }^{18}$. \\ Juan A. Sánchez-Margallo ${ }^{18} \cdot$ Amir Szold $^{19} \cdot$ Helmut Weiss $^{13} \cdot$ Michael Weiss $^{13} \cdot$ Ricardo Zorron $^{15} \cdot$ Nicole D. Bouvy $^{3}$
}

Received: 1 February 2019 / Accepted: 6 February 2019 / Published online: 15 February 2019

(c) The Author(s) 2019

\begin{abstract}
Background Laparoscopic surgery changed the management of numerous surgical conditions. It was associated with many advantages over open surgery, such as decreased postoperative pain, faster recovery, shorter hospital stay and excellent cosmesis. Since two decades single-incision endoscopic surgery (SIES) was introduced to the surgical community. SIES could possibly result in even better postoperative outcomes than multi-port laparoscopic surgery, especially concerning cosmetic outcomes and pain. However, the single-incision surgical procedure is associated with quite some challenges.

Methods An expert panel of surgeons has been selected and invited to participate in the preparation of the material for a consensus meeting on the topic SIES, which was held during the EAES congress in Frankfurt, June 16, 2017. The material presented during the consensus meeting was based on evidence identified through a systematic search of literature according to a pre-specified protocol. Three main topics with respect to SIES have been identified by the panel: (1) General, (2) Organ specific, (3) New development. Within each of these topics, subcategories have been defined. Evidence was graded according to the Oxford 2011 Levels of Evidence. Recommendations were made according to the GRADE criteria.

Results In general, there is a lack of high level evidence and a lack of long-term follow-up in the field of single-incision endoscopic surgery. In selected patients, the single-incision approach seems to be safe and effective in terms of perioperative morbidity. Satisfaction with cosmesis has been established to be the main advantage of the single-incision approach. Less pain after single-incision approach compared to conventional laparoscopy seems to be considered an advantage, although it has not been consistently demonstrated across studies.

Conclusions Considering the increased direct costs (devices, instruments and operating time) of the SIES procedure and the prolonged learning curve, wider acceptance of the procedure should be supported only after demonstration of clear benefits.
\end{abstract}

Keywords Single incision $\cdot$ Laparoscopy $\cdot$ Laparoscopic surgery $\cdot$ Consensus $\cdot$ Statement $\cdot$ Recommendation

Laparoscopic surgery changed the management of numerous surgical conditions. It was associated with many advantages over open surgery, such as decreased postoperative pain, faster recovery, shorter hospital stay and excellent cosmesis. Since two decades single-incision endoscopic surgery (SIES) was introduced to the surgical community. Early reports described the placement of multiple trocars

Yannick M. Meyer

y.meyer2384@gmail.com

Extended author information available on the last page of the article through one incision with sometimes retraction of organs utilizing trans-abdominal sutures. Later, newly developed special devices were introduced to facilitate SIES.

SIES could possibly result in even better postoperative outcomes than multi-port laparoscopic surgery, especially concerning cosmetic outcomes and pain. However, the single-incision surgical procedure is associated with quite some challenges. One of the technical challenges of SIES is the loss of triangulation and therefore conflict of the instruments. Also, in obese patients a limited maneuverability of the SIES port might cause a problem. The retraction of solid 
organs could be sometimes problematic as well. Further, because of the use of a single entry port and thereby also a need of a larger incision size, more wound infections and incisional hernias might occur after SIES. Finally, a prolonged learning curve is a necessity to optimally execute technically demanding procedures such as SIES.

After considering all these aspects, doubts have arisen among surgeons whether SIES is a "way to go" in surgery. The main question is whether there is enough evidence to support an adoption of SIES as a safe and feasible surgical approach and consequently, if it should be routinely performed. Besides the clinical outcomes, a cost aspect should be taken into account as well. The European association for endoscopic surgery (EAES) has gathered all available evidence on this topic, and its' members have discussed and commented on the found evidence during a consensus meeting at the EAES congress in June 2017. In this consensus paper, we try to outline the advantages and disadvantages of SIES, addressing the general aspects of this surgical procedure, as well as the organ specific issues.

The report of this consensus statement applies to general surgeons, particularly those with special interest in minimally invasive surgery, policymakers, researchers, medical device manufacturers and general practitioners, to aid in patient decision making.

\section{Methods}

An expert panel of surgeons has been selected and invited to participate in the preparation of the material for a consensus meeting on the topic SIES, which was held during the EAES congress in Frankfurt, June 16, 2017. Two surgeons with vast experience in endoscopic surgery (NB, SM-C) and by an epidemiologist (AP) coordinated the project. The members of the panel had met three times (February, March, June 2017) before the final presentation at the EAES congress, to discuss the strategy, preparation and progress of the project.

The material presented during the consensus meeting was based on evidence identified through a systematic search of literature according to a pre-specified protocol. Three main topics with respect to SIES have been identified by the panel: (1) General, (2) Organ specific, (3) New development. Within each of these topics, subcategories have been defined. 'General' topics included (a) instruments, (b) devices and (c) ergonomics. 'Organ specific' topics included (a) cholecystectomy, (b) appendectomy, (c) colon, (d) rectum-abdominal approach, (e) bariatrics, (f) spleen and adrenal, (g) liver and pancreas, (h) upper GI-benign, (i) upper GI-malignant and (j) abdominal wall-inguinal and ventral hernia. 'New development' topics included (a) single-port intragastric, (b) single-port through natural orifice and (c) single-port and robotics. For each (sub) category, a member of a team has been assigned, responsible for the search, methodological appraisal of the articles, data extraction and presentation of the material.

IRB approval and written consent were not required for this paper.

\section{Search}

The participants received a search specific to their (sub) topic. The composition of the searches has been discussed and approved by a librarian at the Maastricht University Library (The Netherlands). Searches included a query for searching the PubMed database; another query has been designed to search EMBASE (using OVID). The participants were also encouraged to search beyond the scope of the given search and consider papers for inclusion if found by an alternative way as well.

\section{Selection of articles}

The participants have been asked to note the number of studies identified by the search, number of included and excluded studies and the reason for exclusion. They were instructed to include studies on SIES applicable to their (sub) topic. SIES procedures with and extra trocar planned from the beginning of the surgery, especially for advance procedures, were considered SIES. Inclusion criteria were: randomized controlled trials (RCTs), prospective studies, studies in patients older than 12 years. Exclusion criteria were: retrospective studies, case reports, studies in children under 12 years of age. The expectation was that for some categories it might be difficult to find randomized trials or even prospective studies. As safety is an important issue after introduction of new medical devices and operating techniques, it has been decided that in case of a serious lack of information concerning safety after the first selection, also case reports or retrospective case series with large numbers, if they added important information, could be reviewed.

\section{Data extraction and appraisal of the methodological quality of the studies}

A uniform excel database template for entering the data extracted from the selected papers has been provided to all participants. Important outcome measures with respect to SIES have been included in the template: operating time, postoperative pain, need for additional ports, conversion to open surgery, hospital stay, postoperative pain, cosmesis, adverse events and mortality. The participants were encouraged to add any other outcome measure if necessary. The template contained predefined fields for noting important information for each study, like population characteristics, detailed information about the surgical procedure, 
experience level of the surgeons, etc. and the results for each outcome, including the effect size and statistical significance where appropriate. In case of malignancy, the presence of free margins, the histological specimen surrogate, the length of follow-up and tumor recurrence/disease free-survival rate were noted as well.

The methodological quality of the randomized controlled trials has been assessed with the Cochrane Collaboration's tool for assessing risk of bias [1]. The appropriate fields to fill in the scores were included in the excel template.

\section{Grading of evidence/definitions}

After data extraction, the teams worked out a presentation on their topic and a more comprehensive summary of their findings in a Word file. All presentations were made according to the same pre-specified format. Included in the presentations were: flowchart of the selection of articles, description of the population, summary of the papers, conclusions, statements and recommendations. The teams were asked to present preferably the results of the RCTs, potentially the results of a meta-analysis.

The teams were also specifically asked to state any adverse events, even if reported in studies of lower methodological quality. The definition of safety involved occurrence of peri- and postoperative mortality and morbidity (serious side effects).

With each "Statement" the level of evidence has been given. Grading of evidence was based on "The Oxford 2011 levels of evidence" [2], which defines five levels, ranging from Level 1 (highest evidence) to Level 5 (lowest evidence). This tool allows for grading levels down on the basis of study quality, imprecision, inconsistency between studies, etc. It also allows to grade up in case of a large or very large effect size. The participants were well informed about this. They were asked to take the outcomes of the Cochrane Collaboration's tool for assessing risk of bias into account while grading the evidence provided by RCTs. With each 'Recommendation', the level of recommendation has been given. This was defined as 'strong' or 'weak' or 'no recommendation' according to the GRADE criteria [3].

To make sure that all teams use the same wording and phrasing, an instruction has been given on how to formulate statements and recommendations. The following wording has been proposed for the formulation of the statements: for statements based on level 1 evidence the terms 'is', 'is associated' and 'has' were to be used, for statements based on levels 2 to 5 of evidence the word 'might' was reserved. For strong recommendations, the words 'must' or 'should' had to be used and for weak recommendations the words 'could' or 'might' [4].

For the outcome 'safety', we have chosen also to use the term 'seems comparable' in the statements supported by
Level 1 evidence. The reason for this is that clinical trials are usually underpowered to provide definitive results. This is to be expected, as the sample size for the clinical trials is mostly calculated on the basis of other outcomes, rather than mortality and serious adverse events.

\section{Results}

The literature searches were performed up to February 2017.

\section{General topics}

\section{Instruments}

\section{Statements}

1. A combination of straight and curved, or straight and articulating instruments might result in improved skills acquisition in single-incision endoscopic surgery. (LoE4)

2. A combination of two curved or two articulating instruments might be associated with worse task performance. (LoE4)

There are several types of instruments available on the market for single-port laparoscopy. These are straight, articulating, curved or double curved instruments. Sixteen studies were retrieved from the literature, in which the use of these instruments has been evaluated. These are one network meta-analysis [5], 13 RCTs [6-18] and 2 prospective studies [19, 20].

In the network meta-analysis, straight instrumentation was compared with curved or articulating instruments in the context of cholecystectomy. Significantly lower odds for addition of extra ports has been found when straight instruments were used (odds ratio (OR) 17.48, 95\% confidence interval (CI) 4.03-75.74). This estimate is not very precise considering the broad interval estimates. Also in favor of the straight instruments was a shorter duration of surgery (mean difference (MD) - 32.53 min, 95\% CI - 24.23 to - 40.83). The 13 randomized trials showed conflicting results but in general, a combination of straight and curved or articulating instruments resulted in improved task performance. In the two selected prospective studies, a better task performance was achieved by the use of straight over double curved and straight/curved over double curved instruments.

The above-mentioned studies have many methodological shortcomings. In 13 studies, the evaluation was done with a box trainer task assessment [6-18]; moreover, in five studies the tasks were performed by medical students [8, $9,12,15,16]$. In one randomized trial, in which straight instruments were compared with articulating instruments 
in 150 laparoscopic cholecystectomies, the external validity was limited due to untypical dissection of Calot's triangle [14]. Another randomized trial which found that the use of straight/curved instruments lead to a better task performance than the use of double curved instruments, the laparoscopic nephrectomies were done in porcine models [6].

In general, the level of evidence provided by those studies is low. A combination of instruments including a straight component might result in better task performance, at least during the learning curve. Individual surgeons may, however, become acquainted with specific types of instruments.

\section{Recommendations}

1. The use of a combination of one straight and one curved/ articulating instrument could be suggested during the learning curve of single-incision endoscopic surgery.

Grade of recommendation: Weak.

\section{Devices}

\section{Statements}

1. Reusable metal access devices for single-incision endoscopic surgery available nowadays might be associated with longer suturing task completion time compared to specific disposable devices. (LoE3)

Very limited research data are available on different devices which can be used for a single-port laparoscopic surgery (Fig. 1) [21-34]. The search yielded up one randomized trial only, which compared X-Cone, SILS ${ }^{\mathrm{TM}}$ Port and GelPOINT devices [35]. X-Cone was associated with longer suturing task completion time compared to SILS ${ }^{\mathrm{TM}}$ or GelPOINT, otherwise no differences were found. A literature search including the grey literature provided some information on 12 devices, 10 of which are available on the market. Most devices allow the use of straight, curved and articulating instruments. Two devices are reusable [36].

In the randomized trial which compared X-Cone versus SILS ${ }^{\text {TM }}$ Port versus GelPOINT, 20 novices and junior surgeons participated and the assessors were blinded. Concerning the cutting task, similar completion time across groups was found. Concerning the suturing task, disposable devices were associated with shorter completion times. Further, similar performance scores across groups were found.

In conclusion, the level of evidence is very low. Disposable devices may be associated with shorter duration of specific tasks.

\section{Recommendations}

1. For the selection of access devices in single-incision endoscopic surgery, one could consider associated costs, taking into account that specific reusable metal devices available nowadays may be associated with longer task completion.

Grade of recommendation: Weak.

\section{Ergonomics}

\section{Statements}

1. SIES might be associated with a more neutral posture of the surgeon's head and higher workload than conventional laparoscopic approach during video-assisted thoracic surgery. (LoE4)

2. Based on bench tests, SIES might be associated with a higher surgeon's muscle activity and wrist's radial/ ulnar range of motion than conventional laparoscopic approach. (LoE5)

3. Based on bench tests, articulating instruments might be associated with higher surgeon's workload, muscle activity and wrist's radial/ulnar range of motion than straight laparoscopic instruments during SIES. (LoE5)

The literature search identified 12 studies [12, 15, 37-46] investigating the ergonomics of a single-port laparoscopic procedure. Due to a lack of larger randomized controlled trials on this topic, surveys of expert opinion and systematic reviews have also been considered. Included were nine studies, which compared SIES with conventional laparoscopy (five of which were randomized), two surveys and one systematic review. The studies are relatively small, the maximum number of subjects per study is 24 , and the maximum number of participants in the surveys is 78 .

In seven of these studies, a box trainer was used for the evaluation. One study used a porcine model for nephrectomy. Five studies focused on the eye-hand coordination tasks, one study on the intracorporeal suturing and one study on dissection tasks. In one study, video-assisted thoracoscopic surgery was performed. Several different types of instruments have been used, two straight instruments (four studies), one straight and one articulating instrument (three studies), two articulating instruments (three studies), two pre-bent instruments (one study). In one study, a robotic platform was involved (Single-port, multichannel surgical platform-SPSP, Spider Surgical Platform, TransEnterix). The use of the following surgical ports was reported, SILS ${ }^{\mathrm{TM}}$ port (Covidien) (two studies), TriPort ${ }^{\mathrm{TM}}$ Access System (Olympus) (one study) and GelPOINT ${ }^{\mathrm{TM}}$ System (Applied 


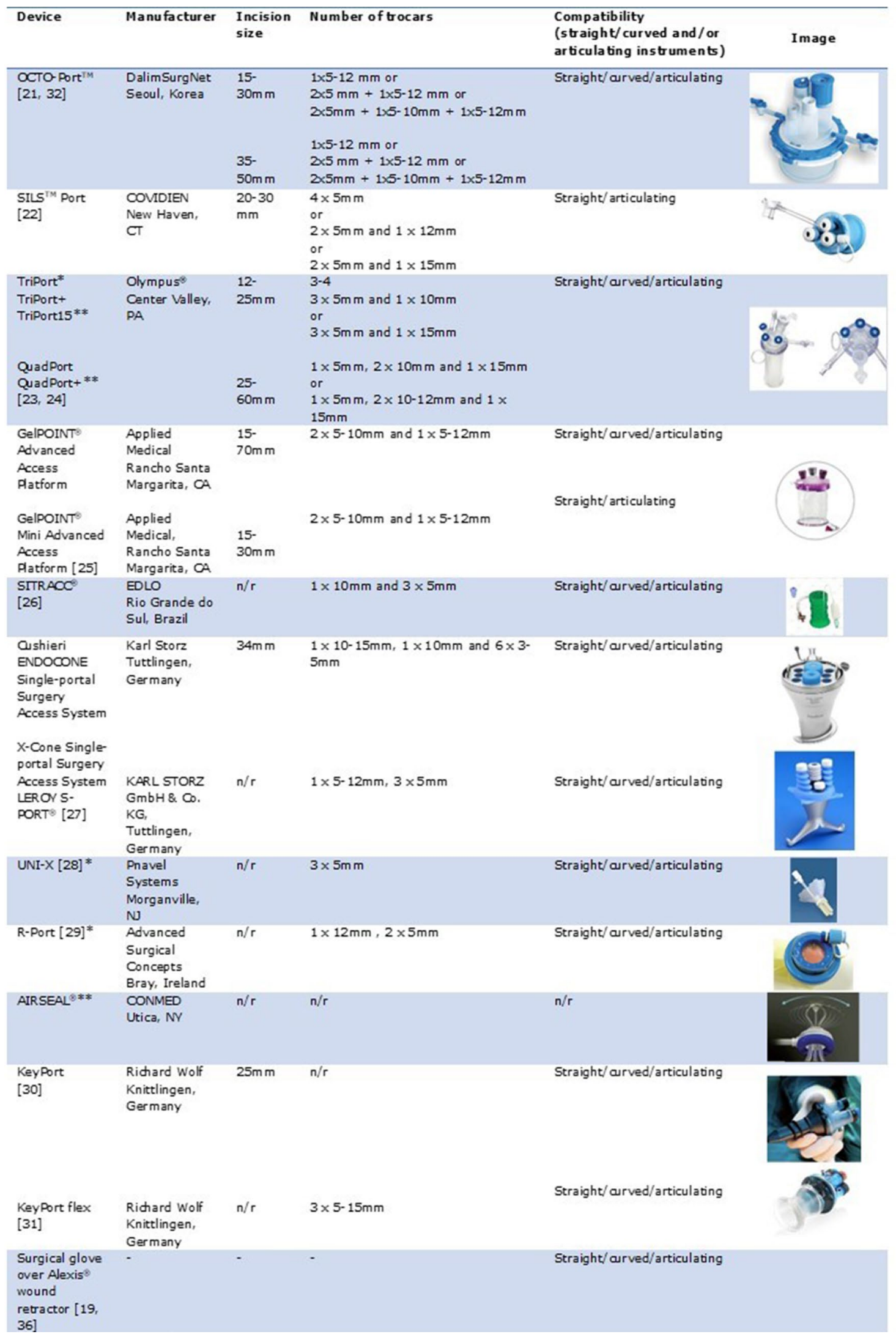

Fig. 1 Devices. *Probably retracted. **Brochure not available on the manufacturer's Web site; $n / r$ not reported 
Medical) (three studies). In 2 studies, the use of three trocars through the same incision was reported.

From the 12 selected studies, nine studies were focused on comparing the ergonomics of both SIES and conventional laparoscopic instruments, two surveys evaluated the opinion of experienced surgeons regarding the ergonomic aspects of the SIES approach, and one study reviewed the ergonomic limitations imposed by SIES in comparison to multi-port laparoscopic surgery.

These are some of the main conclusions: (a) the headtrunk rotation and viewing direction are improved using SIES; (b) workload, muscle activity, and wrist's radial/ulnar range of motion are higher with SIES than with conventional laparoscopy; (c) workload, muscle activity and wrist's radial/ulnar range of motion are higher using articulating instruments than straight laparoscopic instruments during SIES; (d) the use of SILSTM port leads to a higher wrist's radial/ulnar range of motion than using GelPOINT ${ }^{\mathrm{TM}}$ during SIES.

The identified evidence is of low quality, whereas some of the studies presented conflicting results. The ergonomic analyses on SIES robotic surgery are scarce. New studies with a larger number of participants, more complex tasks and performed in real conditions are required to inform on ergonomic parameters in single-port laparoscopy.

Recommendations No recommendation.

\section{Organ specific topics}

\section{Cholecystectomy}

Statements In selected patients (elective cholecystectomy in patients with $\mathrm{BMI}<35$ ):

1. SIES cholecystectomy is feasible and seems safe compared to four-port laparoscopic cholecystectomy. (LoE1)

2. SIES cholecystectomy is associated with better cosmesis, lower postoperative pain and longer operative time in comparison with four-port laparoscopic cholecystectomy (LC). (LoE1)

3. In SIES cholecystectomy, length of hospital stay and quality of life are comparable to four-port laparoscopic cholecystectomy. (LoE1)

SIES cholecystectomy is a new concept in minimally invasive surgery. The access to the operative field is gained through the natural scar of the umbilicus, which makes this procedure even less invasive than the standard laparoscopic approach. Surgeons all over the world are still exploring the concept of single-port surgery. SIES cholecystectomy is the most frequently performed procedure with a single-port approach to date.
11 RCTs were selected for review [47-57]. There are pooled data available of the results of nine of the selected RCTs $(n=860)$ as these were recently included in a systematic review with a meta-analysis [58]. Also, recently the results of a large international multi-center non-inferiority trial $(n=600)$ were published [56]. Additionally, a smaller randomized trial $(n=64)$ was found [57].

All RCTs compared SIES cholecystectomy with conventional four-port laparoscopic cholecystectomy (LC). The total population consists of 1524 adult patients, and mean age is comparable across the studies and also for the SIES and LC group, ranging from 46 to 50 years. All patients have ASA I-III grades. Most of the studies included only patients with $\mathrm{BMI}<30 \mathrm{~kg} / \mathrm{m}^{2}$ or $<35 \mathrm{~kg} / \mathrm{m}^{2}$. One small study ( $\mathrm{n}=34)$ used a $\mathrm{BMI}<40 \mathrm{~kg} / \mathrm{m}^{2}$ as an inclusion threshold. Previous abdominal surgery and the presence of acute cholecystitis were exclusion criteria in all studies. The follow-up period ranged from 1 to 12 months, only one study $(n=60)$ had a longer follow-up, up to 16 months.

Compared to laparoscopic cholecystectomy, cosmesis was significantly better after a SIES procedure. This was according to the meta-analysis and also according to the results of the non-inferiority trial, although in this trial the surgeons rated the cosmetic results of the conventional LC group as better compared to patients self-assessment. The smaller randomized study found no difference in cosmetic results. This study and the pooled data of the nine RCTs showed significantly lower scores of postoperative pain for SIES. In the non-inferiority trial, no difference was found. All results suggested a significantly longer operating time for the SIES procedure, with mean difference ranging from 15 to $30 \mathrm{~min}$. The length of hospital stay and quality of life were comparable for both procedures. Both, the metaanalysis and the non-inferiority trial, found no difference for these outcomes.

Mortality did not occur in any of the studies. According to the meta-analysis of the nine RCTs, there was a higher risk of severe adverse events in the SIES group than in the LC group. In these pooled data, serious adverse events included bile duct injury, re-operations, intra-abdominal collections or bile leaks requiring drainage or infected intra-abdominal collections. However, a bile duct injury occurred in two patients only, in one patient after a SIES procedure and in one patient after a LC procedure. In the large non-inferiority trial and the smaller randomized trial, no difference in severe adverse events was found (no bile duct injuries occurred). The meta-analysis data showed a higher risk of mild adverse events in the SIES group but statistical significance was not reached. In the non-inferiority trial, no difference was found.

There was a significantly higher need of additional ports in the SIES group according to the meta-analysis, but this was actually due to the results of one of the nine pooled studies, in which 17 of 60 patients needed an extra 
umbilical access during SIES. In the non-inferiority trial, no difference in the use of additional ports was found. No difference was found in conversion to open cholecystectomy. There were seven port-site hernias reported in the SIES group and one in the LC group out of 430 patients in each arm, in the nine trials included in the meta-analysis. In the non-inferiority trial, the absolute numbers were six and three, respectively.

The meta-analysis of the nine trials and the large noninferiority trial provided no evidence on costs. The smaller randomized trial suggested earlier return to work and less need for use of analgesics in the SIES group, whereas the costs of the SIES procedure were higher. In the non-inferiority trial, approximately equal amount of analgesics was used in SIES and LC groups.

Overall, evidence on SIES cholecystectomy suggests better cosmetic results and less postoperative pain when compared to standard LC. On the other hand, the operating time is longer. Concerning morbidity, discrepant results were found. The pooled data of nine trials showed a higher risk of adverse events after the SIES procedure, whereas the non-inferiority trial showed that SIES was non-inferior to LC in terms of safety. This non-inferiority trial was primarily designed to prove non-inferiority of the SIES procedure compared to LC regarding morbidity within 60 days after surgery. The sample size calculation was based on this, considering a clinically significant difference of $4 \%$. It was conducted in six countries and included 600 patients. It is the largest trial in which the outcomes of patients were compared who were enrolled according to exactly the same inclusion/exclusion criteria and who were treated under same conditions in comparable circumstances. Although in a meta-analysis the data are being pooled only in case of clinical and statistical homogeneity between the studies, still there might be differences, which can influence the outcomes. One important issue to mention is the surgical experience of the participating surgeons. In the non-inferiority trial, the first operator performed at least 50 cholecystectomies and had experience in at least 15 cases with SIES cholecystectomy. From the nine trials included in the metaanalysis, in five of them the surgeons had previous experience in SIES, three mention only experience in laparoscopic surgery, and one trial gives no information on this topic. In one RCT, the difference in the experience level of surgeons is mentioned as a study limitation. Another point to mention is the patients' BMI. In the non-inferiority trial, only patients with BMI lower than 30 were included. Some other trials included also patients with BMI until 35 (or even 40).

No statement can be made regarding the difference in occurrence of common bile duct lesions since overall incidence of common bile duct lesions is very low. No statement can be made on risk of port-site hernia due to short follow-up.
Regarding costs of the SIES procedure, very little evidence was found.

\section{Recommendations}

1. SIES cholecystectomy could be performed if a patient is looking for better cosmesis and less pain compared to conventional four-port laparoscopic cholecystectomy in patients with a $\mathrm{BMI}<35$.

Grade of recommendation: Weak.

\section{Appendectomy}

Statements In selected patients (non-perforated appendicitis):

1. SIES appendectomy is feasible and seems to be safe compared to standard laparoscopy. (LoE1)

2. SIES appendectomy is associated with better cosmetic outcomes, shorter hospital stay and earlier return to work compared to standard laparoscopy. (LoE1)

3. SIES appendectomy is associated with outcomes comparable to standard laparoscopy with regard to operating time and postoperative pain. (LoE1)

Over the past years laparoscopic appendectomy (LA) has become the treatment of choice for acute appendicitis. The laparoscopic procedure is associated with less postoperative pain, lower postoperative complication rates and earlier recovery, compared to open appendectomy. Single-incision endoscopic surgery in which the number of ports is reduced seems to be suitable for appendectomy in non-perforated appendicitis. To assess the presumed benefits and safety of this procedure, several studies have already been conducted in which SIES appendectomy (SIEA) is compared to conventional laparoscopic appendectomy.

12 RCTs in which patients were randomized to receive either SIEA or conventional LA were eligible for the review [59-70]. Trials in which extra sutures, trocars or K-wires were used were excluded. The results of the 12 studies were pooled in a meta-analysis for several outcomes, when the data were suitable for pooling. Members of the consensus team who were responsible for this topic have conducted the meta-analysis according to the guidelines from the PRISMA statement for reporting systematic reviews and meta-analyses, with a purpose to publish these results in detail as a separate publication (yet to be published).

The total study population consists of 1524 patients, 759 patients underwent SIEA and 765 patients underwent conventional LA. The mean age is 30,6 years and 32,4 years, respectively. The ASA grades were reported in three studies only $(n=247)$, and most patients have a score ASA I. 
The mean BMI is $23,1 \mathrm{~kg} / \mathrm{m}^{2}$ (SIEA) and $23,6 \mathrm{~kg} / \mathrm{m}^{2}$ (LA). The surgical experience was inconsistently reported. Two trials reported that the surgeons had performed more than 25 SIEA $(n=75)$ and more than 20 SIEA $(n=195)$ procedures, respectively, in the past. Two studies $(n=271)$ reported that all participating surgeons were experienced, but did not further quantify the experience. In one trial $(n=77)$, it was stated that more experienced surgeons were operating on SIEA patients. The follow-up duration varied considerably between the studies, ranging from 14 days to 24 months. Only two out of twelve studies had a follow-up duration longer than 6 months, namely 20,8 months $(n=102)$ and 24 months $(n=120)$.

The pooled data (five studies, $n=484$ ) showed significantly better postoperative cosmetic scores in the SIEA group compared to LA group. There was no difference in postoperative pain at 12,24 and $48 \mathrm{~h}$ postoperatively (eight studies, $n=1411$ ). The operating time ( 11 studies, $n=1437$ ) was similar in both groups, with an average of $52 \mathrm{~min}$ in the SIEA group and 49 min in the LA group. Hospital stay (11 studies, $n=1295$ ) was significantly shorter in the SIEA group, with a mean difference of 0,11 days $(27,4 \mathrm{~min})$. Patients also returned earlier to work after the SIEA procedure (four studies, $n=449$ ), the mean difference was 0,61 days.

No mortality was reported in any of the studies. The results of all 12 studies $(n=1524)$ were pooled for the outcome 'adverse events'. There was no difference in the occurrence of serious adverse events (SAEs) or mild adverse events (MAEs) between the groups. In the SIEA group, there were 14 SAEs compared to 13 SAEs in the LA group. The occurrence of MAEs was 59 in the SIEA group and 68 in the LA group. This difference was no statistically significant. Three patients developed a port-site hernia (seven studies, $\mathrm{n}=702$ ); all three were in the SIEA group.

There was no difference in conversion rates to open appendectomy. In the SIEA group, significantly more additional ports were used compared to the LA group, namely 22 to 2 , respectively (seven studies, $n=801$ ). One study found significantly higher costs for the single-port procedure compared to conventional LA $(n=120)$ [70]. No further information on costs could be retrieved.

In conclusion, patients who underwent single-port appendectomy were more satisfied with the cosmetic outcomes than patients who underwent a conventional laparoscopic approach. There was, however, no difference in postoperative pain. The hospital stay and return to work were both in favor of the single-port approach, but the profit is relatively small when expressed in absolute figures. The single-port approach required more use of additional ports. There was no difference in adverse events.

The data on port-site hernias are limited due to a short follow-up in most studies. No statement is formulated on this outcome. Cost comparison could not be made.

\section{Recommendations}

1. SIES appendectomy in non-perforated appendicitis could be performed if patient is looking for better cosmesis and earlier return to work.

Grade of recommendation: Weak.

\section{Colon}

Statements In selected patients $(<\mathrm{T} 4$ or tumors $<5 \mathrm{~cm}$, $\mathrm{BMI}<35$, no previous abdominal surgery):

(1) SIES colectomy might be safe and feasible. (LoE2)

(2) SIES colectomy might be associated with same oncological surrogate outcome as multi-port laparoscopic colectomy, but long-term data on oncological outcomes are lacking. (LoE2)

(3) SIES colectomy might have comparable perioperative outcomes as multi-port laparoscopic colectomy regarding morbidity and complication rate. (LoE2)

Since the first reported laparoscopic colectomy in 1991, the safety of the laparoscopic approach in colorectal surgery and equivalent or even better oncologic outcomes in colorectal cancer have been demonstrated. The advantages of laparoscopic colectomy over open surgery include shorter hospital stay and faster recovery of bowel function, reduced blood loss, less postoperative pain and better cosmesis. SIES could even maximize the specific benefits of laparoscopic approach, especially regarding incisional trauma, postoperative pain and wound related complications.

Three RCTs were found in the literature in which single-port (SP) colectomy was compared to multi-port (MP) colectomy in patients with colorectal neoplasms [71-73]. The number of patients included in the randomized trials is relatively low. Therefore, also prospective and retrospective studies (with prospective data collection) conducted on large cohorts of patients were reviewed for complications and other relevant outcomes [74-102].

One RCT included 200 patients, 100 in each treatment arm, whereas the other two RCTs were rather small, with 50 and 16 patients. Surgeries included right and left colectomies, sigmoid resections and low anterior resections. Included were patients with tumors $<\mathrm{T} 4$ or tumors $<5 \mathrm{~cm}$, $\mathrm{BMI}<35 \mathrm{~kg} / \mathrm{m}^{2}$, without previous abdominal surgery. Patients with previous history of peritonitis, ASA score 4 and emergency surgery were excluded. Overall, no differences were found for perioperative and short-term postoperative outcomes. The mean number of resected lymph nodes was comparable between the SP and MP groups. There were no deaths, and the complication rates were similar. In one 
trial $(n=50)$, the patients in the SP group had significantly lower median pain score on day 1 and day 2 . The median hospital stay in the SP group in this trial was shorter than in the MP group.

The randomized trials focused on short-term outcomes after surgery. The reported oncological outcomes are "surrogate" outcomes, such as number of lymph nodes harvested, free margins and length of the specimen. The largest trial $(n=200)$ is still on-going [72]; the disease-free survival 5 years after surgery will be reported after termination of the follow-up.

The results from the other included studies support the findings of the randomized trials. In terms of safety, all studies indicate that single-incision approach in colonic surgery is a safe and feasible. The oncological outcomes, whether surrogate oncological outcomes or recurrence rates or disease-free survival, all show results comparable to standard laparoscopy for cancer. Operative times were inconsistent across the studies. This might be associated with selection of patients for SP surgery and also by the experience of surgeons with this technique. Some studies reported on faster postoperative recovery and shorter hospital stay after SP. Postoperative pain-control seemed to be also more favorable for the SP group. The complication rates did not seem to differ between the SP and MP approaches. The cosmetic results were not specifically reported in the studies.

\section{Recommendations}

(1) In selected patients ( $<\mathrm{T} 4$ or tumors $<5 \mathrm{~cm}, \mathrm{BMI}<35$, no previous abdominal surgery) SIES colonic resection could be offered to patients as an equally safe and effective alternative compared to multi-port colonic surgery with comparable histological surrogate outcome.

Grade of recommendation: Weak.

\section{Rectum}

Statements In selected patients (tumor $<4 \mathrm{~cm}, \mathrm{BMI}<30$ ):

(1) SIES rectum resection might be a safe procedure with comparable outcomes as multi-port laparoscopy, if carried out by experienced surgeons. (LoE2)

(2) The postoperative pain might be lower after SIES rectum resection compared to multi-port laparoscopy. (LoE2)

(3) The histological surrogate outcome for malignant indications might be comparable between SIES rectum resection and multi-port laparoscopy. (LoE2)
Laparoscopic surgery for rectal disease has been proven to be equivalent to open surgery in randomized studies in the last years. Nonetheless, the adoption of SIES rectal surgery by surgeons is still low, possibly due to the complexity of the procedures and an extended learning curve. However, as a large extraction site or planned diversion stoma site is needed in many cases for colorectal resections, there can be a rationale for the use the single access for rectal resections.

One RCT [103] $(\mathrm{n}=40)$ and six comparative studies [104-109] $(n=670)$, in which SIES and multi-port rectal surgery were compared were retrieved from the literature. Three of the six comparative studies started the SIES rectal resection already with one extra port. All studies included both, low anterior and abdomino-perineal resections. In most of the studies, the indication was malignant rectal cancer. Two studies also included benign rectal disease, besides the rectal cancer. Included were mainly patients with a BMI $<30 \mathrm{~kg} / \mathrm{m}^{2}$ and tumors sized less than $4 \mathrm{~cm}$.

The RCT was a small pilot study in which patients with rectal cancer were randomized either to SIES $(n=20)$ or multi-port laparoscopic surgery $(n=20)$. Patients after SIES rectal resection had significantly less postoperative pain during the first 4 days than patients undergoing a multi-port laparoscopic rectal resection. The incision length was significantly shorter in the SIES group. All other outcomes were similar between the groups, including operating time, blood loss, morbidity and mortality. The short-term oncological outcomes were also comparable.

The other studies reported on similar outcomes to those of the RCT. The clinical postoperative outcomes and the short-term oncological outcomes were similar between the groups. In a relatively large study $(n=55$ SIES; $n=327$ conventional laparoscopy), SIES was associated with shorter operating time, less postoperative pain, faster recovery and earlier discharge. Shorter hospital stay was reported in one other study as well $(n=100)$. One study reported shorter abdominal incisions, less pain and better satisfaction with cosmetic results after SIES $(n=57)$. One study estimated also the costs; these were similar for both procedures.

\section{Recommendations}

(1) Single-incision endoscopic rectal surgery in selected patients (tumor size $<4 \mathrm{~cm}$ and $\mathrm{BMI}<30$ ) could be performed by experienced laparoscopic surgeons safely offering less postoperative pain and comparable histological surrogate outcome in comparison with multiport laparoscopy.

Grade of recommendation: Weak. 


\section{Bariatrics}

Statements In selected patients $(\mathrm{BMI}<50$, no previous surgery, xipho-umbilical distance less than $25 \mathrm{~cm}$ ):

(1) SIES bariatric surgery might be as safe as the conventional laparoscopic approach when performed by skilled surgeons, with comparable weight loss results in short-term follow up. (LoE3)

(2) SIES sleeve gastrectomy, compared to the conventional laparoscopic procedure, might be associated with less postoperative pain and a better cosmetic result, but with an increase in operative time. (LoE2)

(3) SIES gastric bypass, compared to the conventional laparoscopic procedure, might be associated with less postoperative pain and a better cosmetic result, but with an increase in operative time. (LoE3)

Laparoscopic approach is nowadays the gold standard in surgical treatment of morbid obesity. Minimally invasive surgery has been proven beneficial regarding postoperative morbidity and mortality in bariatric surgery [110]. As SIES procedure might reduce the level of postoperative pain, it is being explored as a surgical option in patients with morbid obesity, despite the fact that other SIES procedures are preferably not being performed in patients with a BMI $>35 \mathrm{~kg} /$ $\mathrm{m}^{2}$. In case of sleeve gastrectomy, a larger incision is used anyway to extract the remaining stomach tissue so one can reduce the number of further incisions in the abdominal wall using the single-incision approach. In case of gastric bypass, it seems, however, more complicated to use SIES because of the requirement for intracorporeal sutures and anastomoses.

The literature search identified 10 studies in which patients underwent a SIES procedure for the treatment of morbid obesity. All are comparative studies, evaluating SIES versus multi-port conventional laparoscopy (CL). In eight studies, the performed procedure is sleeve gastrectomy [111-118] and in two studies gastric bypass $[119,120]$. Liver retraction was achieved by either liver suspension tape attached to two Prolene sutures or a 3-mm mini liver retractor. Furthermore, one systematic review published in 2015 was identified [121]. However, we were not able to retrieve any pooled data as no meta-analysis was undertaken. The authors included also studies in which laparoscopic gastric banding was used. As this procedure is being used rarely nowadays, studies on SIES laparoscopic gastric banding were not evaluated in our analysis. Only one of the studies from our literature search is an RCT [111], the other studies are three prospective and six retrospective comparative studies. The prospective studies were reviewed for patient-related outcomes, and the retrospective studies were reviewed for major complications.
The RCT is a pilot study in which 30 patients were randomized either to SIES $(n=15)$ or CL $(n=15)$ sleeve gastrectomy. Included were patients with $\mathrm{BMI}<50 \mathrm{~kg} / \mathrm{m}^{2}$ and xipho-umbilical distance less than $25 \mathrm{~cm}$. All patients are female except for two males in the SIES group. The mean BMI is $44,35 \mathrm{~kg} / \mathrm{m}^{2}$ and $45,52 \mathrm{~kg} / \mathrm{m}^{2}$ in the SIES and CL groups, respectively, the mean ASA score is 2,41 in the SIES and 2,33 in the CL group. There were no intra- or postoperative complications in either group; all patients were discharged on the third day post-surgery with instructions for a liquid diet. No differences were found regarding pain at rest, operative time or weight loss at 6 months. Patients in the SIES group reported significantly less pain during movement on the first and second day postoperatively compared to the patients in the CL group, but on the third day no significant difference in pain scores was found. The SIES patients reported a significantly higher aesthetical satisfaction at 1, 3 and 6 months.

In two prospective studies with sleeve gastrectomy, with even number of patients undergoing SIES and CL, singleincision technique was found to be technically feasible with results that were mostly similar to those obtained with multi-port conventional laparoscopy. In the larger study $(n=600)$, the SIES procedure was scored as less painful with better cosmesis. Three patients in the SIES group developed an incisional hernia compared to no patients in the CL group within a follow-up of up to 2 years. In the smaller study $(n=42)$, no differences in morbidity or hospital stay were found between the groups. Operative time was higher in the SIES group. There was one conversion to laparoscopic surgery in the single-incision group. In the retrospective studies with gastric sleeve surgery $(n=147$ SIES), no major complications or occurrence of incisional hernias were reported. The longest follow-up was 1 year.

Only one of the two studies on SIES gastric bypass surgery was performed prospectively $(n=40$ SIES, $n=100$ $\mathrm{CL}$ ). No difference in complications compared to multiport laparoscopy was found. The operative time was longer in the SIES group. The recovery and weight loss were comparable between the groups. The SIES procedure resulted in better patient satisfaction. The follow-up was up to 12 months. In the retrospective study with gastric bypass surgery $(n=100$ SIES, $n=100 \mathrm{CL}), 18$ patients required an extra skin incision for a $5 \mathrm{~mm}$ port. Complications were equally distributed in the two groups.

No mortality occurred in any of the reviewed studies.

\section{Recommendations}

(1) In a controlled environment of expert bariatric surgeons, single-incision laparoscopic bariatric surgery (sleeve gastrectomy and gastric bypass) could be performed safely in selected patients $(\mathrm{BMI}<50$, no pre- 
vious surgery and xipho-umbilical distance less than $25 \mathrm{~cm}$ ), especially in those concerned about cosmetic results.

Grade of recommendation: Weak.

\section{Spleen and adrenal}

\section{Splenectomy Statements}

In selected patients (estimated spleen weight $\leq 500 \mathrm{~g}$ ):

(1) SIES splenectomy might be considered a safe and feasible surgical approach with perioperative morbidity comparable to standard laparoscopic splenectomy. (LoE4)

(2) SIES splenectomy might be considered superior to standard laparoscopic splenectomy in terms of cosmesis. (LoE4)

(3) SIES splenectomy might be considered to require longer operative time compared to standard laparoscopic splenectomy. (LoE4)

Theoretically, the single-incision technique might be less suitable for splenectomy than for other surgical indications. A practical limitation might be the poor exposure of the lesser sac and the upper pole of spleen. Furthermore, in patients with high body mass index (BMI) or in tall patients, the surgeon might experience difficulty in reaching the spleen.

After the literature search two prospective $[122,123]$ and four retrospective comparative studies [124-127] have been selected for review, in which SIES splenectomy is compared to standard (or reduced port) laparoscopic splenectomy (LS). No randomized clinical trials have been published on this topic, which may be related to the fact that elective splenectomy is a rarely performed operation. As the number of patients included in the prospective studies is relatively small, the results of retrospective studies have been taken into account to document the incidence of complications.

One prospective study which compared SIES $(n=8)$ and standard LS $(n=15)$, included patients with spleen weight less than $500 \mathrm{~g}$ [122]. There was no conversion to open surgery in any group. Operative time was longer for surgery with the SIES technique. There were no differences in intraor postoperative outcomes. Patients in the SIES group were more satisfied with the cosmetic results.

Another prospective study compared SIES $(n=19)$ and three port LS $(n=21)$ [123]. Operative time was longer in the SIES group. One patient in the SIES group had conversion to laparotomy due to bleeding. Postoperative pain was less in patients after SIES. In both groups, one pancreatic fistula occurred.
In the retrospective studies $(\mathrm{n}=72$ SIES and $\mathrm{n}=85 \mathrm{LS})$, no hernia formation was reported during the follow-up period up to maximum 34 months. There was one report of intraoperative gastric wall injury in the SIES group. Bleeding rates seemed equally distributed in both techniques.

Recommendations No recommendation.

\section{Adrenalectomy Statements}

(1) SIES transabdominal adrenalectomy might be considered a feasible surgical approach. (LoE4)

(2) SIES transabdominal adrenalectomy might be considered similar to standard laparoscopic adrenalectomy in terms of perioperative and postoperative outcomes. (LoE4)

Multi-port laparoscopic adrenalectomy is a well-established procedure and can be performed trans- or retroperitoneally for both the left and the right adrenal. SIES for adrenalectomy may be associated with better cosmetic results.

Review of the literature identified one prospective comparative study [128], in which SIES left transperitoneal adrenalectomy was compared to multi-port laparoscopic left transperitoneal adrenalectomy (LA). Also one systematic review and meta-analysis of retrospective studies has been identified, which was published in 2016 [129].

In the selected prospective study, there were 40 patients in each treatment group. None of the SIES patients required conversion to an open procedure. In one case, an additional 5 -mm port was needed for kidney retraction. No differences in operative time, nor postoperative complications were reported. Pain scores were comparable in both groups. Cosmesis was not evaluated.

In the systematic review and meta-analysis, 10 retrospective studies $(n=704)$ were analyzed. The sample size of the studies ranged from 9 to 140 patients. Patients in the SIES group $(n=255)$ had a shorter hospital stay and lower postoperative pain scores than patients in the LA group $(n=449)$. No differences were found in operative time, doses of required analgesics, perioperative complications and conversion rates.

Recommendations No recommendation.

\section{Liver and pancreas}

\section{Liver Statements}

In selected patients (various indications):

(1) SIES liver resection might be performed safely and with comparable outcomes to multi-port laparoscopic 
resection if carried out by experienced surgeons. (LoE3)

(2) SIES liver resection might result in shorter postoperative hospital stay compared to multi-port laparoscopy. (LoE3)

Laparoscopic liver surgery has not been adopted by liver surgeons as much as other laparoscopic operations. Types of laparoscopic liver surgery vary in complexity and difficulty. The most frequent indication for the laparoscopic single-incision technique is benign left-lateral liver diseases, as these are technically less demanding. The potential advantage of single-incision approach might be earlier recovery and reduced scar formation.

One RCT was identified through the literature search, in which single-port (SP) and multi-port (MP) laparoscopic left lateral liver sectionectomies (LLLS) have been compared [130]. Another four comparative studies comparing SP and MP laparoscopic liver surgery were identified [131-134].

In the RCT, all patients were operated on for benign liver diseases and they were assigned either to single-port $(n=19)$ or multi-port $(n=19)$ laparoscopic LLLS. Mean operative times did not differ significantly between groups $(105 \pm 23 \mathrm{~min}$ vs. $90 \pm 27 \mathrm{~min}$ for SP versus MP, respectively). Postoperative hospital stay was significantly shorter in the single-port group ( $2.5 \pm 1.7$ days vs. $4.0 \pm 2.1$ days for SP vs. MP, $\mathrm{p}<0.05$, respectively). No conversion to open surgery was reported, whereas one conversion to multi-port laparoscopy was reported in the SP group. No deaths or clinically relevant complications were reported.

In the four comparative studies, a total of 194 patients underwent either SP $(n=107)$ or MP $(n=87)$ minor liver resections. The surgical procedures were: unroofing of liver cysts, left lateral sectionectomies, common bile duct explorations and laparoscopic part of donor right hepatectomies. Experienced surgeons performed the procedures; however, no clear definition of the grade of experience was provided. No clear procedural advantages could be established. Two studies reported on reduced operative time for SP, whereas no differences were found in other reports. Pain, cosmesis, incidence of port-site hernia and other long-term complications were inconsistently reported.

\section{Recommendations}

(1) SIES minor liver resections could be offered as safe and effective surgery when performed by experienced surgeons compared to conventional laparoscopic approach.

Grade of recommendation: Weak.

\section{Pancreas}

Statements In selected patients (distal pancreatic resection):

(1) SIES pancreatic resection might be performed safely and with comparable outcomes as with multi-port laparoscopy, if carried out by experienced surgeons. (LoE3)

(2) Operating time might be longer for SIES pancreatic resection compared to multi-port laparoscopy. (LoE3)

Laparoscopic distal pancreatectomy is increasingly being performed worldwide, in specialized surgical institutions. Although in a limited extent until now, next to a multi-port (MP) laparoscopy also a single-port (SP) laparoscopic approach in pancreatic surgery is being explored.

There are no RCTs available in the literature. Four comparative studies reporting on a total of 119 patients $(n=50$ SP and $n=69 \mathrm{MP}$ ) were retrieved [135-138].

All studies reported on distal pancreatectomy for both, benign and malignant disease. Experienced surgeons performed the surgeries, but no definition of the grade of experience was reported. Three studies compared the SP technique with a standard four-port left sided pancreatectomy [135-137]. One study compared the SP technique with a robotic MP approach [138]. The operative strategy was comparable between the different groups and centers. The parenchyma dissection, as a critical step of the resection, was carried out by means of an endoscopic linear stapler in all patients.

In one study ( $n=12 \mathrm{SP}, \mathrm{n}=28 \mathrm{MP})$, the mean operative time was documented to be longer in the SP group ( $280 \pm 53 \mathrm{~min}$ vs. $187 \pm 87 \mathrm{~min}$ ). The same article reported on shorter mean hospital stay after MP laparoscopic distal pancreatectomy $(12.2 \pm 5.4$ days vs. $8.3 \pm 4.7$ days $)$. This was due to a higher proportion of patients with pancreatic fistulas in the SP group. These patients namely had a longer hospital stay compared to patients without fistulas (14.7 \pm 7.7 days vs. $7.9 \pm 3.0$ days). All other procedural outcome parameters did not differ between the two groups. Only three pancreatic fistulas $(2.5 \%)$ were reported. There is no sufficient data to allow assessment of postoperative pain, cosmesis, hernia and procedural costs.

\section{Recommendations}

(1) SIES distal pancreatic resections could be offered as an equally safe and effective procedure compared to multiport laparoscopy, when performed by experienced surgeons.

Grade of recommendation: Weak. 


\section{Upper gastrointestinal tract-benign}

Statements In selected patients (Nissen fundoplication, ASA 1 and 2):

(1) SIES Nissen fundoplication might be considered a safe and effective procedure in the short term. (LoE3)

(2) SIES Nissen fundoplication might have better cosmetic results compared to standard laparoscopy. (LoE3)

(3) SIES Nissen fundoplication might be associated with longer operative time compared to standard laparoscopy. (LoE3)

(4) SIES Nissen fundoplication might require hospital stay comparable to standard laparoscopy. (LoE3)

Laparoscopic fundoplication has become the standard surgical treatment of gastroesophageal reflux. It has several advantages when compared to open fundoplication, such as less postoperative pain, decreased mortality and shorter hospital stay. SIES might also lead to better cosmetic results due to a single-port entry instead of multiple entries. This single-port technique is being explored now for utilization in laparoscopic antireflux surgery.

Two studies were identified in the literature, which compared the outcomes of single-site Nissen fundoplication with the conventional multi-port laparoscopic fundoplication $[139,140]$. Both studies are reports, one prospective $(n=260)$ and one retrospective $(n=33)$. No RCTs have been published yet.

Both studies reported on patients with comparable age, sex and BMI distribution. ASA grades were low, mostly grade 2. The mean BMI varied from 27 to $29 \mathrm{~kg} / \mathrm{m}^{2}$. The mean follow-up was 26-28 weeks. The prospective study analyzed the postoperative outcomes of consecutive patients, 130 patients underwent SIES fundoplication and 130 conventional laparoscopic fundoplication (CL). Symptom resolution was comparable between the groups. Cosmesis scores were superior for the SIES procedure, and $96 \%$ of patients were very satisfied with the cosmetic outcomes after SIES. Operative time was longer for the SIES procedure, $146 \mathrm{~min}$ (median) versus 101 min (median). Duration of hospital stay was comparable. There were no conversions to open surgery in the SIES group; there were seven conversions in the CL group. Further, no notable complications occurred.

In the retrospective report, the outcomes of 15 SIES and 18 laparoscopic Nissen fundoplications were compared. All patients in the SIES group achieved symptomatic relief of gastroeshophageal reflux. Mean operative time was longer in the SIES group, namely 182 min (range 111-273) versus 129 min (range 101-184). Duration of hospital stay was comparable. There were no conversions to open surgery in the CL group, whereas six of the 15 patients in the SIES group required insertion of two to four additional ports.
There was no perioperative mortality or morbidity in either group. A single surgeon who had no previous experience in SIES Nissen fundoplication performed all the procedures in this study.

In conclusion, according to these reports SIES Nissen fundoplication seems to be safe and feasible, with similar symptom improvement and superior cosmesis when compared to multi-port laparoscopic procedure. No conclusions could be drawn with regard to postoperative pain and port-site hernia occurrence after SIES fundoplication. The follow-up in both reports was relatively short. For a sound comparison, randomized controlled trials with a longer follow-up time are necessary. One of the challenges for the optimal performance of this technique might be a longer learning curve.

\section{Recommendations}

(1) SIES antireflux surgery (Nissen fundoplication) could be offered as a procedure being performed safely in selected patients (ASA 1 or 2).

Grade of recommendation: Weak.

\section{Upper gastrointestinal tract malignant}

Statements In selected patients (early distal gastric cancer - stage $\mathrm{Ia} / \mathrm{Ib}, \mathrm{BMI}<25$ ):

(1) SIES gastrectomy might be as safe in terms of postoperative complications as multi-port laparoscopic gastrectomy. (LoE4)

(2) SIES gastrectomy might be associated with shorter hospital stay than multi-port laparoscopic gastrectomy. (LoE4)

(3) SIES gastrectomy might have similar oncological surrogate outcomes as multi-port laparoscopic gastrectomy. (LoE4)

Single-incision laparoscopic surgery has been explored, among other indications as an option for performing gastrectomy in patients with gastric cancer.

No randomized trials have been found in the literature on this topic. However, some studies addressed the feasibility and safety of single-port gastrectomy (SIESG). Three comparative studies were found in which laparoscopic single-port distal gastrectomy for early gastric cancer was compared to multi-port (or reduced port) laparoscopic gastrectomy (MLDG) [141-143]. All studies reported on early gastric cancer, stage $\mathrm{Ia} / \mathrm{Ib}$, in patients with $\mathrm{BMI}<25 \mathrm{~kg} / \mathrm{m}^{2}$. These studies included a total of 188 patients in the SIESG group and 181 in the MLDG group. These were retrospective 
studies of prospectively collected data on SIESG. The data were matched with the data of patients who underwent MLDG. There was no difference in number of harvested lymph nodes. Operative time was comparable. One study reported shorter hospital stay and all studies reported faster recovery, including less pain and earlier oral intake after SIESG. Postoperative complications after 30 days were comparable; only one study ( $\mathrm{n}=90$ SIESG, $\mathrm{n}=85$ MLDG) reported on survival, the 5 years overall survival rates were comparable between SIESG and MLDG [143]. There were no differences in incidence of incisional hernia in this study.

Recommendations No recommendation.

\section{Abdominal wall}

\section{Inguinal hernia Statements}

In selected patients (elective primary unilateral and bilateral inguinal hernia):

(1) SIES TEP is feasible and seems a safe procedure when performed by experienced surgeons. (LoE1)

(2) SIES TEP might require longer operative time than conventional TEP. (LoE2)

(3) The postoperative pain after SIES TEP might be comparable with conventional TEP. (LoE2)

(4) Cosmetic scores might be better with SIES TEP compared to conventional TEP. (LoE3)

(5) The recurrence rate might be comparable between SIES TEP and conventional TEP. (LoE4)

(6) SIES TEP procedure might have higher costs than conventional TEP. (LoE4)

Single-incision hernia repair was developed with the intention to improve cosmetic outcomes and to lessen postoperative pain by reduced number of trocars, when compared to common multi-trocar procedure. Despite the potential benefits, until now this procedure has not gained much acceptance.

Selection of the papers from the literature included studies on primary, both unilateral and bilateral inguinal hernia in an elective setting, performed in a totally extraperitoneal (TEP) fashion. TEP was the most commonly performed procedure for hernia repair with a single-incision technique. Very limited information only could be found on the transabdominal preperitoneal (TAPP) approach. The literature search identified four RCTs [144-147] $(n=398)$ on this topic and one meta-analysis [148]. Only three of the four RCTs were included in this meta-analysis as one of the trials was published later. Moreover, many studies that were included in this meta-analysis did not pass our selection criteria.

All four RCTs compared SIES versus conventional laparoscopic TEP. All trials included 99 or 100 patients. In two trials, a longer operative time was reported for SIES TEP, this was statistically significant in one trial only. Pain scores were significantly better after SIES TEP in two trials, resp. $2 \mathrm{~h}, 1$ day and 7 days postoperatively. One trial reported significantly better cosmetic scores at 6 -week follow-up. No serious complications occurred. No recurrence was reported, even in the follow-up period up to 21 months. Authors of one study mention additional costs of US $\$ 340$ per patient for the single-port repair when original Triport ${ }^{\mathrm{TM}}$ was used.

Several other prospective or retrospective studies reporting on single-incision inguinal hernia repair have been identified [149-156]. These studies were viewed for complications. Remarkably, one of the case series reported on an exceptionally high incidence of recurrent hernia (31/200) and port-site incisional hernia (15/200). A single surgeon performed all TEPs in this study. No deaths or serious morbidity was reported in any of the studies.

To summarize, based on current data it seems that SIES TEP is safe and feasible, although the benefits for the patient might be disputable. Disadvantages might be extra costs and a prolonged learning curve.

\section{Recommendations}

(1) SIES inguinal hernia repair (TEP) could be offered to patients who are concerned about cosmesis as a safe and feasible approach when performed by experienced surgeons.

Grade of recommendation: Weak.

\section{Ventral hernia}

\section{Statements}

(1) SIES ventral hernia repair might be feasible and safe in comparison with laparoscopic ventral hernia repair (LVHR). (LoE3)

(2) Operative time in SIES ventral hernia repair might be comparable to LVHR. (LoE3)

(3) Overall recurrence rate after SIES ventral hernia repair might be comparable to LVHR. (LoE3)

The rationale for the development of single-incision laparoscopic ventral herniorrhaphy was to decrease incisional hernia sites in patients prone to develop ventral hernias, to reduce wound complications and to improve cosmesis.

No randomized controlled trials comparing SIES ventral hernia repair with laparoscopic ventral hernia repair (LVHR) have been identified. Only one comparative study was found [157] and two prospective series reporting on 50 or more patients $[158,159]$. 
In these studies, SIES ventral hernia repair was described in various clinical settings, including postoperative ventral hernias in obese patients with advanced age. Adhesiolysis was also feasible using this approach. In the comparative study, 15 SIES and 18 LVHR procedures were performed. The adhesion grade according to Zühlke was noted at surgery, and this was comparable between the procedures. The mean operative time was $78,2 \pm 31,2 \mathrm{~min}$ for SIES and $73,5 \pm 25,4 \mathrm{~min}$ for LVHR. After SIES, two seromas and one hematoma were reported, whereas two small bowel injuries and two seromas occurred with LVHR. One recurrent hernia was reported after SIES within a follow-up of up to 31 months. No recurrence occurred in the LVHR group within a follow-up of up to 42 months. No port-site hernias developed in either group. In the prospective series, no serious complications occurred, except for a bladder perforation; no port-site hernias were reported within a follow-up of 28 to 34 months.

\section{Recommendations}

(1) Experienced surgeons could offer SIES ventral hernia repair to patients since it is considered feasible and seems as safe as conventional laparoscopic ventral hernia repair.

Grade of recommendation: Weak.

\section{New developments}

\section{Intragastric surgery}

Statements In selected patients (tumor location near esophagogastric junction or pre-pyloric):

(1) SIES intragastric surgery might be feasible for the resection of submucosal stromal tumors. (LoE5)

A new development for gastric resection, an intragastric approach using a single-port device might have some advantages compared to conventional laparoscopy with multiple ports. However, no comparative studies on this topic have been found in the literature. Three case series [160-162] and one case report [163] could be identified, with a total of 32 patients. In all studies, the indications for surgery were submucosal stromal tumors, although the preoperative diagnosis was not always possible. There was heterogeneity with regard to the operating method, the type of devices, placement on the abdominal wall (umbilicus or left flank), the method for resecting the tumor (stapler or energy devices) and the use of intraoperative gastroscopy assisting the procedure. The devices used in the different series were a glove trocar with an Alexis wound retractor, the $\mathrm{OCTO}^{\mathrm{TM}}$ port and
TriPortPlus ${ }^{\mathrm{TM}}$. The follow-up varied from 3 to 20 months, whereas the largest study $(n=21)$ reported on a follow-up of 19 months. The tumor locations were cardia, fundus and pylorus. In two studies with the largest cohorts, the mean tumor size was $2,4 \pm 0,7 \mathrm{~cm}(\mathrm{n}=21)$ and $2,7 \mathrm{~cm}$, range $2,3-3,8(\mathrm{n}=7)$. The mean BMI was $22,6 \pm 2,0 \mathrm{~kg} / \mathrm{m}^{2}(\mathrm{n}=21)$ and $26,28 \mathrm{~kg} / \mathrm{m}^{2}$, range $21-35(\mathrm{n}=7)$. The mean operating time was $68,6 \pm 12 \mathrm{~min}(\mathrm{n}=21)$ and 83,6 min, range 70-105 $(\mathrm{n}=7)$. The mean hospital stay was $4,9 \pm 1,7$ days $(\mathrm{n}=21)$ and 5,4 days, range 4-6 $(n=7)$.

The authors of the selected papers reported on the singleincision intragastric resection for the submucosal tumors as being feasible and with an acceptable number of complications. No mortality or major complications occurred. Surgeons did not experience any technical restrictions compared to their experience with conventional laparoscopic surgery. However, there are no randomized trials published yet with a head to head comparison of the single-port approach versus conventional laparoscopic approach to show and weigh the benefits and potential disadvantages.

Recommendations No recommendation.

\section{Single-port surgery through natural orifice}

\section{Statements}

(1) Natural orifice single access transvaginal cholecystectomy might have the potential to be safe and feasible and might represent a further advantage in terms of cosmesis and pain perception, compared to SIES. (LoE4)

Natural Orifice Transluminal Endoscopic Surgery (NOTES) is linked to the concept of surgery where access to the operative field is gained through natural orifices including the mouth, the anus and the vagina, without skin incisions. By definition, it is both technically and technologically demanding and surgeons all around the world have been exploring the possible applications for this technique and its limitations with caution.

Six eligible studies investigating single access NOTES have been identified [164-169]. The total population consists of 249 patients. Three of the included studies are comparative studies, and one is a randomized trial [164]. The randomized trial $(n=40)$ compared NOTES to standard laparoscopic surgery. The two non-randomized studies $(n=131)$ compared standard laparoscopy, SIES and NOTES. The remaining three papers are case series reporting on preliminary results of NOTES $(n=78)$. The performed procedures were cholecystectomy (transvaginal, transumbilical, transgastric), appendectomy (transvaginal, transumbilical, 
transgastric) and total mesorectal excision. The comparative studies explored merely cholecystectomy.

Transvaginal cholecystectomy (TVC) was performed in total in 45 patients. No conversion occurred in TVC procedures, neither to laparoscopic nor to open surgery. The operative time was similar when compared to transumbilical laparoscopic cholecystectomy (TLC). No deaths occurred. One case of intra-abdominal abscess was reported in the TVC group. In the randomized trial $(n=40)$, the postoperative pain was significantly lower in the TVC group compared to the TLC group $(\mathrm{p}<0.001)$. In another prospective comparative study $(\mathrm{n}=51)$, similar result was found.

Evidence on NOTES was generally of low quality. The few cases of transgastric-cholecystectomy, NOTES-total mesorectal excision, transgastric-appendectomy and transvaginal-appendectomy have been described only as preliminary results in case series. Comparative studies focused on single access transvaginal cholecystectomy. In total, merely 45 TVCs have been reported. This technique might have the potential to become an alternative to standard laparoscopic or single-incision laparoscopic cholecystectomy, providing improved cosmesis and less postoperative pain. However, high level of evidence is still lacking.

Recommendations No recommendations.

\section{Single-port and robotics}

Statements In selected robotic surgery (elective cholecystectomy, compatible with the da Vinci Si Surgical System):

(1) Robotic SIES might be as safe and effective as standard laparoscopy but might be associated with a longer operating time. (LoE2)

(2) Robotic SIES might offer an advantage in terms of cosmesis but not in terms of pain perception, compared to standard laparoscopy. (LoE2)

(3) The risk of incisional hernia for robotic SIES compared to standard laparoscopy might be higher. (LoE2)

SIES robotic cholecystectomy (SIRC) is a recently introduced technique that is gaining acceptance among surgeons. The possibility to tackle the technical challenges of singleincision access by using robotic technology seems to be of great interest. The literature search identified thirteen studies with a total of 1411 patients [170-182]. Two studies were randomized controlled trials $[170,171](n=136$ and $n=60$ ), and three were non-randomized comparative studies [172-174] $(\mathrm{n}=790)$. The two RCTs and a large nonrandomized study $(n=678)$ compared SIRC with multi-port laparoscopic cholecystectomy (MPLC). Two smaller studies $(\mathrm{n}=112)$ compared SIRC with single-incision laparoscopic cholecystectomy (SILC). The remaining eight papers $(n=425)$ were case series. All studies reported on elective cholecystectomy.

The RCT that included 136 patients had a follow-up of 3 months. The patients in the SIRC group had superior cosmesis satisfaction and body image perception $(\mathrm{p}<0.05)$. However, there was no difference in quality of life. Operative time was longer in the SIRC group compared to multiport laparoscopy (61 min versus $44 \mathrm{~min}, \mathrm{p}<0.001)$. There was no difference in complication rates. In the RCT that included 60 patients, the cosmetic score 1 month postoperatively was higher for SIRC $(\mathrm{p}<0.001)$. There was no difference in pain. A wound infection was reported in two SIRC patients. In this trial, patients were approached again 15 months after the end of the study to assess the occurrence of incisional hernia. One patient in the SIRC group developed a hernia, none in the MPLC group.

The third study, which compared SIRC to MPLC $(n=678)$, was a large comparative study with a retrospective analysis of prospectively maintained data. The majority, of the patients $(n=415,61 \%)$, underwent a SIRC procedure. A single surgeon did all surgeries in this study. The total operative time was comparable between the groups. Hospital stay was shorter in the SIRC group (1,9 vs. 2,4 days). There were more wound infections in the SIRC group $(3,9 \%$ vs. $1,1 \%)$. The rate of incisional hernia was higher in the SIRC group compared to MPLC group (27 vs. 5).

Other studies included in the review reported a higher rate of conversion to open surgery, higher rate of wound infections and wound abscesses for SIRC when compared to MLCP or SILS. There were neither deaths nor major complications. In the prospective series, 5 bleedings and 1 bowel injury were reported after the SIRC.

Two comparative studies reported on costs $[173,174]$. One study reported comparable costs of instruments $(\$ 1268$ for SIRC and \$1282 for SILC). Another study reported on a total cost for SIRC. In this study, cost refers to the expense incurred to the hospital. There was no difference in variable direct supply cost or variable direct labor cost. However, fixed direct cost was significantly higher in the robotic group (\$3137 for SIRC and \$384 for SILC). The total cost was found to be higher in the SIRC group (\$8961 for SIRC and $\$ 5379$ for SILC). This is, according to the authors due to higher fixed costs, higher cost of administrative personnel for the operating room, and an increased operative time.

The single-incision robotic cholecystectomy seems to be a safe and effective technique. One point of concern though is that in several studies a higher incidence of incisional hernias after SIRC was demonstrated. Another point of concern could be the high costs associated with SIRC. 
Recommendations No recommendations.

\section{Conclusions}

After viewing and discussing all the given evidence, the members of the EAES panel have formulated the following conclusions:

(1) In general, there is a lack of high level evidence and a lack of long-term follow-up in the field of singleincision endoscopic surgery.

(2) The available evidence does not give a sufficient platform to formulate strong recommendations.

(3) If surgeons are willing to start with SIES, it is important to take into account the selection criteria of patients used in the studies for the specific topics.

(4) In single-incision surgery for advanced procedures, the use of an extra-trocar from the beginning should be considered SIES.

(5) In selected patients, the single-incision approach seems to be safe and effective in terms of perioperative morbidity.

(6) Satisfaction with cosmesis has been established to be the main advantage of the single-incision approach.

(7) Less pain after single-incision approach compared to conventional laparoscopy seems to be considered an advantage, although it has not been consistently demonstrated across studies.

(8) There is a lack of evidence on the occurrence of incisional hernia after SIES in the long-term. Available data do not allow definitive conclusions regarding wound-related morbidity.

(9) In selected patients, the oncological surrogate outcomes seem similar to that of the conventional laparoscopic approach; however, there is a lack of long-term data.

(10) Considering the increased direct costs (devices, instruments and operating time) of the SIES procedure and the prolonged learning curve, wider acceptance of the procedure should be supported only after demonstration of clear benefits.

\section{Compliance with ethical standards}

Disclosures Dr. Salvador Morales-Conde, Dr. Andrea Peeters, Drs. Yannick Meyer, Dr. Stavros A. Antoniou, Dr. Isaías Alarcón del Agua, Dr. Alberto Arezzo, Dr. Simone Arolfo, Dr. Amir Ben Yehuda, Dr. Luigi Boni, Dr. Elisa Cassinotti, Dr. Giovanni Dapri, Dr. Tao Yang, Dr. Sofie Fransen, Dr. Antonello Forgione, Dr. Shahab Hajibandeh, Dr. Shahin Hajibandeh, Dr. Michele Mazzola, Dr. Marco Migliore, Drs.
Christof Mittermair, Drs. Doris Mittermair, Dr. Antonio MorandeiraRivas, Dr. Carlos Moreno-Sanz, Dr. Andrea Morlacchi, Dr. Eran Nizri, Drs. Myrthe Nuijts, Dr. Jonas Raakow, Dr. Francisco M. SánchezMargallo, Dr. Juan A. Sánchez-Margallo Drs. Amir Szold, Drs. Helmut Weiss, Drs. Michael Weiss, Dr. Ricardo Zorron and Dr. Nicole D. Bouvy $\mathrm{MD} \mathrm{PhD}^{3}$ have no conflicts of interest or financial ties to dislose.

Open Access This article is distributed under the terms of the Creative Commons Attribution 4.0 International License (http://creativeco mmons.org/licenses/by/4.0/), which permits unrestricted use, distribution, and reproduction in any medium, provided you give appropriate credit to the original author(s) and the source, provide a link to the Creative Commons license, and indicate if changes were made.

\section{References}

1. Higgins J, Green S (2011) Cochrane Handbook for Systematic Reviews of Interventions I Cochrane Training. http://training. cochrane.org/handbook. Accessed 1 Apr 2018

2. CEBM (2015) OCEBM Levels of Evidence I CEBM. http://www. cebm.net/ocebm-levels-of-evidence/

3. Guyatt GH, Oxman AD, Kunz R, Falck-Ytter Y, Vist GE, Liberati A, Schünemann HJ, GRADE Working Group (2008) Going from evidence to recommendations. BMJ 336:1049-1051. https://doi. org/10.1136/bmj.39493.646875.AE

4. Lomotan EA, Michel G, Lin Z, Shiffman RN (2010) How "should" we write guideline recommendations? interpretation of deontic terminology in clinical practice guidelines: survey of the health services community. BMJ Qual Saf 19:509-513. https ://doi.org/10.1136/qshc.2009.032565

5. Antoniou SA, Morales-Conde S, Antoniou GA, Pointner R, Granderath F-A (2016) Single-incision laparoscopic cholecystectomy with curved versus linear instruments assessed by systematic review and network meta-analysis of randomized trials. Surg Endosc 30:819-831. https://doi.org/10.1007/s00464-015-4283-X

6. Stolzenburg J-U, Kallidonis P, Oh M-A, Ghulam N, Do M, Haefner T, Dietel A, Till H, Sakellaropoulos G, Liatsikos EN (2010) Comparative assessment of laparoscopic single-site surgery instruments to conventional laparoscopic in laboratory setting. J Endourol 24:239-245. https://doi.org/10.1089/ end.2009.0296

7. Botden S, Strijkers R, Fransen S, Stassen L, Bouvy N (2011) The use of curved vs. straight instruments in single port access surgery, on standardized box trainer tasks. Surg Endosc 25:27032710. https://doi.org/10.1007/s00464-011-1633-1

8. Santos BF, Reif TJ, Soper NJ, Hungness ES (2011) Effect of training and instrument type on performance in single-incision laparoscopy: results of a randomized comparison using a surgical simulator. Surg Endosc 25:3798-3804. https://doi.org/10.1007/ s00464-011-1791-1

9. Miernik A, Schoenthaler M, Lilienthal K, Frankenschmidt A, Karcz WK, Kuesters S (2012) Pre-bent instruments used in single-port laparoscopic surgery versus conventional laparoscopic surgery: comparative study of performance in a dry lab. Surg Endosc 26:1924-1930. https://doi.org/10.1007/s0046 4-011-2129-8

10. Rimonda R, Tang B, Brown SI, Cuschieri A (2012) Comparison of endoscopic task performance with crossed versus uncrossed straight and curved instruments through a single port. Surg Endosc 26:3605-3611. https://doi.org/10.1007/s0046 4-012-2379-0 
11. Corker HP, Singh P, Sodergren MH, Balaji S, Kwasnicki RM, Darzi AW, Paraskeva P (2015) A randomized controlled study to establish the effect of articulating instruments on performance in single-incision laparoscopic surgery. J Surg Educ 72:1-7. https ://doi.org/10.1016/j.jsurg.2014.08.004

12. Riggle JD, Miller EE, McCrory B, Meitl A, Lim E, Hallbeck MS, LaGrange CA (2015) Ergonomic comparison of laparoscopic hand instruments in a single site surgery simulator with novices. Minim Invasive Ther Allied Technol 24:68-76. https://doi. org/10.3109/13645706.2014.946426

13. Sánchez-Margallo FM, Matos-Azevedo AM, Pérez-Duarte FJ, Enciso S, Martín-Portugués ID-G (2014) Performance analysis on physical simulator of four different instrument setups in laparo-endoscopic single-site (LESS) surgery. Surg Endosc 28:1479-1488. https://doi.org/10.1007/s00464-013-3337-1

14. Zhao L, Wang Z, Xu J, Wei Y, Guan Y, Liu C, Xu L, Liu C, Wu B (2016) A randomized controlled trial comparing single-incision laparoscopic cholecystectomy using a novel instrument to that using a common instrument. Int J Surg 32:174-178. https://doi. org/10.1016/j.ijsu.2016.06.045

15. Wang D, Shi L-Q, Wang J-M, Jiang X-H, Ji Z-L (2016) Comparison of different sets of instruments for laparoendoscopic singlesite surgery in a surgical simulator with novices. ANZ J Surg 86:264-269. https://doi.org/10.1111/ans.12447

16. Lukovich P, Sionov VB, Kakucs T (2016) Training with curved laparoscopic instruments in single-port setting improves performance using straight instruments: a prospective randomized simulation study. J Surg Educ 73:348-354. https://doi.org/10.1016/j. jsurg.2015.10.013

17. Balaji S, Singh P, Sodergren MH, Corker HP, Kwasnicki RM, Darzi A, Paraskeva P (2015) A randomized controlled study to evaluate the impact of instrument and laparoscope length on performance and learning curve in single-incision laparoscopic surgery. Surg Innov 22:621-628. https://doi.org/10.1177/15533 50615572657

18. Xu AA, Zhu JF, Xie X, Su Y (2014) Mechanical evaluation of articulating instruments and cross-handed manipulation in laparoendoscopic single-site surgery. Surg Innov 21:398-402. https ://doi.org/10.1177/1553350613509727

19. Autorino R, Kim FJ, Rane A, De Sio M, Stein RJ, Damiano R, Micali S, Correia-Pinto J, Kaouk JH, Lima E (2011) Lowcost reusable instrumentation for laparoendoscopic single-site nephrectomy: assessment in a porcine model. J Endourol 25:419424. https://doi.org/10.1089/end.2010.0415

20. Chow G, Chiu CJ, Zheng B, Panton ON, Meneghetti AT (2016) Rigid vs articulating instrumentation for task completion in single-port surgery. Am J Surg 211:903-907. https://doi. org/10.1016/j.amjsurg.2016.01.017

21. DalimSurgNET. http://www.dalimsurg.net/mobile/html/produ ct.html. Accessed 26 Mar 2017

22. Covidien SILS ${ }^{\mathrm{TM}}$ Port. http://www.medtronic.com/content/dam/ covidien/library/us/en/product/trocars-and-access/sils-port-trans anal-use-info-sheet.pdf. Accessed 19 Mar 2017

23. TriPort+ (WA58050T) | Olympus America I Medical. http://medical.olympusamerica.com/products/trocars/tripo rt-wa58050t?utm_source $=$ olympusamerica.com\&utm_mediu $\mathrm{m}=$ web\&utm_campaign=triport\&utm_content=less_triport. Accessed 26 Mar 2017

24. Laparoscopic Surgery, TriPort, Single Port, Omniport, QuadPort hand access. http://www.advancedsurgical.ie/Products/Defau lt.87.html. Accessed 19 Mar 2017

25. GelPOINT ® Advanced Access Platforms. http://www.appli edmedical.com/Content/Resources/GelPoint/SC01711.pdf. Accessed 19 Mar 2017
26. Trocater Portal Sitracc $10 \mathrm{~mm}$ e $5 \mathrm{~mm}$ - Edlo. http://www.edlo. com.br/produto/trocater-portal-sitracc-10mm-e-5mm/. Accessed 19 Mar 2017

27. Online Catalog I KARL STORZ Endoskope I Bhutan. https:// www.karlstorz.com/bt/en/online-catalog.htm. Accessed 19 Mar 2017

28. Cianchi F, Staderini F, Badii B (2014) Single-incision laparoscopic colectomy: a new era in the treatment of colorectal cancer? In: Colorectal cancer-surgery, diagnostics and treatment. InTech, Chennai

29. OPUS Press Release. http://www.advancedsurgical.ie/Rest_of_ World_Home_Page/Default.547.html/OPUS_Press_Release/ Default.616.html. Accessed 26 Mar 2017

30. The cost-effective route to modern surgery. http://www.richardwolf.com/broschueren/Surgery/B_774_KeyPort_I13_GB.pdf. Accessed 26 Mar 2017

31. The flexible solution New flexibility for transanal and transabdominal surgery. http://www.richard-wolf.com/broschueren/ Surgery/_B_797_KeyPort_flex_VIII15_en.pdf. Accessed 26 Mar 2017

32. (2017) Access Transformer OCTO PORT V2. https://www.afsmedical.com/sites/default/files/product_downloads/octo_port_ brochure_englisch.pdf. Accessed 3 Apr 2018

33. Asakuma M, Hayashi M, Komeda K, Shimizu T, Hirokawa F, Miyamoto Y, Okuda J, Tanigawa N (2011) Impact of single-port cholecystectomy on postoperative pain. Br J Surg 98:991-995. https://doi.org/10.1002/bjs.7486

34. Han H-J, Choi S-B, Kim W-B, Choi S-Y (2011) Single-incision multiport laparoscopic cholecystectomy. Arch Surg 146:68. https ://doi.org/10.1001/archsurg.2010.287

35. Matos-Azevedo AM, Martín-Portugués IDG, Pérez-Duarte FJ, Sánchez-Hurtado M, Sánchez-Margallo FM (2014) Comparison of single access devices during cut and suturing tasks on simulator. J Surg Res 192:356-367. https://doi.org/10.1016/j. jss.2014.06.017

36. Zhao L, Wang Z, Xu J, Wei Y, Guan Y, Xu L, Liu C, Wu B (2016) A randomized controlled trial comparing single-incision laparoscopic cholecystectomy using a novel instrument to that using a common instrument. Int J Surg 32:174-178. https://doi. org/10.1016/j.ijsu.2016.06.045

37. Alleblas CCJ, Velthuis S, Nieboer TE, Sietses C, Stegeman DF (2015) The physical workload of surgeons. Surg Innov 22:376381. https://doi.org/10.1177/1553350615577480

38. Bertolaccini L, Viti A, Terzi A (2015) Ergon-trial: ergonomic evaluation of single-port access versus three-port access videoassisted thoracic surgery. Surg Endosc 29:2934-2940. https:// doi.org/10.1007/s00464-014-4024-6

39. Esposito C, Najmaldin A, Schier F, Yamataka A, Ferro M, Riccipetitoni G, Czauderna P, Ponsky T, Till H, Escolino M, Iaquinto M, Marte A, Saxena A, Settimi A, Rothenberg S (2014) Work-related upper limb musculoskeletal disorders in pediatric minimally invasive surgery: a multicentric survey comparing laparoscopic and sils ergonomy. Pediatr Surg Int 30:395-399. https://doi.org/10.1007/s00383-013-3437-y

40. Han WK, Tan YK, Olweny EO, Yin G, Liu Z-W, Faddegon S, Scott DJ, Cadeddu JA (2013) Comparison between magnetic anchoring and guidance system camera-assisted laparoendoscopic single-site surgery nephrectomy and conventional laparoendoscopic single-site surgery nephrectomy in a porcine model: focus on ergonomics and workload profiles. J Endourol 27:490 496. https://doi.org/10.1089/end.2012.0484

41. McCrory B, Lowndes BR, Wirth LM, de Laveaga AE, LaGrange CA, Hallbeck MS (2012) Ergonomic evaluation of laparoendoscopic single-site surgery ports in a validated laparoscopic 
training model. Work 41 Suppl 1:1884-1890. https://doi. org/10.3233/WOR-2012-0402-1884

42. Montero PN, Acker CE, Heniford BT, Stefanidis D (2011) Single incision laparoscopic surgery (SILS) is associated with poorer performance and increased surgeon workload compared with standard laparoscopy. Am Surg 77:73-77

43. Morandeira-Rivas A, Millán-Casas L, Moreno-Sanz C, HerreroBogajo ML, Tenías-Burillo JM, Giménez-Salillas L (2012) Ergonomics in laparoendoscopic single-site surgery: survey results. $\mathbf{J}$ Gastrointest Surg 16:2151-2159. https://doi.org/10.1007/s1160 5-012-2021-4

44. Pérez-Duarte FJ, Lucas-Hernández M, Matos-Azevedo A, Sánchez-Margallo JA, Díaz-Güemes I, Sánchez-Margallo FM (2014) Objective analysis of surgeons' ergonomy during laparoendoscopic single-site surgery through the use of surface electromyography and a motion capture data glove. Surg Endosc 28:1314-1320. https://doi.org/10.1007/s00464-013-3334-4

45. Rieder E, Martinec DV, Cassera MA, Goers TA, Dunst CM, Swanstrom LL (2011) A triangulating operating platform enhances bimanual performance and reduces surgical workload in single-incision laparoscopy. J Am Coll Surg 212:378-384. https://doi.org/10.1016/j.jamcollsurg.2010.10.009

46. Tang B, Hou S, Cuschieri SA (2012) Ergonomics of and technologies for single-port lapaxroscopic surgery. Minim Invasive Ther Allied Technol 21:46-54. https://doi.org/10.3109/13645 706.2011.627924

47. Abd Ellatif ME, Askar WA, Abbas AE, Noaman N, Negm A, ElMorsy G, El Nakeeb A, Magdy A, Amin M (2013) Quality-of-life measures after single-access versus conventional laparoscopic cholecystectomy: a prospective randomized study. Surg Endosc 27:1896-1906. https://doi.org/10.1007/s00464-012-2625-5

48. Bucher P, Pugin F, Buchs NC, Ostermann S, Morel P (2011) Randomized clinical trial of laparoendoscopic single-site versus conventional laparoscopic cholecystectomy. Br J Surg 98:16951702. https://doi.org/10.1002/bjs.7689

49. Jorgensen LN, Rosenberg J, Al-Tayar H, Assaadzadeh S, Helgstrand F, Bisgaard T (2014) Randomized clinical trial of singleversus multi-incision laparoscopic cholecystectomy. Br J Surg 101:347-355. https://doi.org/10.1002/bjs.9393

50. Lirici MM, Califano AD, Angelini P, Corcione F (2011) Laparoendoscopic single site cholecystectomy versus standard laparoscopic cholecystectomy: results of a pilot randomized trial. Am J Surg 202:45-52. https://doi.org/10.1016/j.amjsurg.2010.06.019

51. Lurje G, Raptis DA, Steinemann DC, Amygdalos I, Kambakamba P, Petrowsky H, Lesurtel M, Zehnder A, Wyss R, Clavien PA, Breitenstein S (2015) Cosmesis and body image in patients undergoing single-port versus conventional laparoscopic cholecystectomy: a multicenter double-blinded randomized controlled trial (SPOCC-trial). Ann Surg 262:728-734. https://doi. org/10.1097/sla.0000000000001474

52. Luna RA, Nogueira DB, Varela PS, Rodrigues Neto Ede O, Norton MJ, Ribeiro Ldo C, Peixoto AM, de Mendonca YL, Bendet I, Fiorelli RA, Dolan JP (2013) A prospective, randomized comparison of pain, inflammatory response, and short-term outcomes between single port and laparoscopic cholecystectomy. Surg Endosc 27:1254-1259. https://doi.org/10.1007/s0046 4-012-2589-5

53. Saad S, Strassel V, Sauerland S (2013) Randomized clinical trial of single-port, minilaparoscopic and conventional laparoscopic cholecystectomy. Br J Surg 100:339-349. https://doi. org/10.1002/bjs.9003

54. Sinan H, Demirbas S, Ozer MT, Sucullu I, Akyol M (2012) Single-incision laparoscopic cholecystectomy versus laparoscopic cholecystectomy: a prospective randomized study. Surg Laparosc
Endosc Percutaneous Tech 22:12-16. https://doi.org/10.1097/ SLE.0b013e3182402448

55. Sulu B, Yildiz BD, Ilingi ED, Gunerhan Y, Cakmur H, Anuk T, Yildiz B, Koksal N (2015) Single port vs. four port cholecystectomy-randomized trial on quality of life. Adv Clin Exp Med 24:469-473. https://doi.org/10.17219/acem/43713

56. Arezzo A, Passera R, Bullano A, Mintz Y, Kedar A, Boni L, Cassinotti E, Rosati R, Fumagalli Romario U, Sorrentino M, Brizzolari M, Di Lorenzo N, Gaspari AL, Andreone D, De Stefani E, Navarra G, Lazzara S, Degiuli M, Shishin K, Khatkov I, Kazakov I, Schrittwieser R, Carus T, Corradi A, Sitzman G, Lacy A, Uranues S, Szold A, Morino M (2017) Multi-port versus single-port cholecystectomy: results of a multi-centre, randomised controlled trial (MUSIC trial). Surg Endosc 31:2872-2880. https ://doi.org/10.1007/s00464-016-5298-7

57. Hajong R, Hajong D, Natung T, Anand M, Sharma G (2016) A comparative study of single incision versus conventional four ports laparoscopic cholecystectomy. J Clin Diagn Res 10:PC06PC09. https://doi.org/10.7860/JCDR/2016/19982.8601

58. Evers L, Bouvy N, Branje D, Peeters A (2017) Single-incision laparoscopic cholecystectomy versus conventional four-port laparoscopic cholecystectomy: a systematic review and metaanalysis. Surg Endosc 31:3437-3448. https://doi.org/10.1007/ s00464-016-5381-0

59. Carter JT, Kaplan JA, Nguyen JN, Lin MYC, Rogers SJ, Harris HW (2014) A prospective, randomized controlled trial of singleincision laparoscopic vs conventional 3-port laparoscopic appendectomy for treatment of acute appendicitis. J Am Coll Surg 218:950-959. https://doi.org/10.1016/j.jamcollsurg.2013.12.052

60. Sozutek A, Colak T, Dirlik M, Ocal K, Turkmenoglu O, Dag A (2013) A prospective randomized comparison of single-port laparoscopic procedure with open and standard 3-port laparoscopic procedures in the treatment of acute appendicitis. Surg Laparosc Endosc Percutaneous Tech 23:74-78. https://doi.org/10.1097/ SLE.0b013e3182754543

61. Teoh AYB, Chiu PWY, Wong TCL, Poon MCM, Wong SKH, Leong HT, Lai PBS, Ng EKW (2012) A double-blinded randomized controlled trial of laparoendoscopic single-site access versus conventional 3-port appendectomy. Ann Surg 256:909914. https://doi.org/10.1097/SLA.0b013e3182765fcf

62. Kye B-H, Lee J, Kim W, Kim D, Lee D (2013) Comparative study between single-incision and three-port laparoscopic appendectomy: a prospective randomized trial. J Laparoendosc Adv Surg Tech 23:431-436. https://doi.org/10.1089/lap.2012.0284

63. Frutos MD, Abrisqueta J, Lujan J, Abellan I, Parrilla P (2013) Randomized prospective study to compare laparoscopic appendectomy versus umbilical single-incision appendectomy. Ann Surg 257:413-418. https://doi.org/10.1097/SLA.0b013e3182 $78 \mathrm{~d} 225$

64. Kang J, Bae BN, Gwak G, Park I, Cho H, Yang K, Kim KW, Han S, Kim H-J, Kim Y-D (2012) Comparative study of a single-incision laparoscopic and a conventional laparoscopic appendectomy for the treatment of acute appendicitis. J Korean Soc Coloproctol 28:304. https://doi.org/10.3393/jksc.2012.28.6.304

65. SCARLESS Study Group, Ahmed I, Cook JA, Duncan A, Krukowski ZH, Malik M, MacLennan G, McCormack K (2015) Single port/incision laparoscopic surgery compared with standard three-port laparoscopic surgery for appendicectomy: a randomized controlled trial. Surg Endosc 29:77-85. https://doi. org/10.1007/s00464-014-3416-y

66. Lee W-S, Choi ST, Lee JN, Kim KK, Park YH, Lee WK, Baek J-H, Lee T-H (2013) Single-port laparoscopic appendectomy versus conventional laparoscopic appendectomy. Ann Surg 257:214-218. https://doi.org/10.1097/SLA.0b013e318273bde4 
67. Pan Z, Jiang X-H, Zhou J-H, Ji Z-L (2013) Transumbilical singleincision laparoscopic appendectomy using conventional instruments. Surg Laparosc Endosc Percutaneous Tech 23:208-211. https://doi.org/10.1097/SLE.0b013e3182827f5d

68. Park J, Kwak H, Kim SG, Lee S (2012) Single-port laparoscopic appendectomy: comparison with conventional laparoscopic appendectomy. J Laparoendosc Adv Surg Tech 22:142-145. https ://doi.org/10.1089/lap.2011.0253

69. Vilallonga R, Barbaros U, Nada A, Sümer A, Demirel T, Fort JM, González O, Armengol M (2012) Single-port transumbilical laparoscopic appendectomy: a preliminary multicentric comparative study in 87 patients with acute appendicitis. Minim Invasive Surg 2012:1-5. https://doi.org/10.1155/2012/492409

70. Villalobos Mori R, Escoll Rufino J, Herrerías González F, Mias Carballal MC, Escartin Arias A, Olsina Kissler JJ (2014) Prospective, randomized comparative study between single-port laparoscopic appendectomy and conventional laparoscopic appendectomy. Cir Esp 92:472-477. https://doi.org/10.1016/j. ciresp.2013.12.013

71. Poon JTC, Cheung C-W, Fan JKM, Lo OSH, Law W-L (2012) Single-incision versus conventional laparoscopic colectomy for colonic neoplasm: a randomized, controlled trial. Surg Endosc 26:2729-2734. https://doi.org/10.1007/s00464-012-2262-z

72. Watanabe J, Ota M, Fujii S, Suwa H, Ishibe A, Endo I (2016) Randomized clinical trial of single-incision versus multiport laparoscopic colectomy. Br J Surg 103:1276-1281. https://doi. org/10.1002/bjs.10212

73. Huscher CG, Mingoli A, Sgarzini G, Mereu A, Binda B, Brachini G, Trombetta S (2012) Standard laparoscopic versus singleincision laparoscopic colectomy for cancer: early results of a randomized prospective study. Am J Surg 204:115-120. https:// doi.org/10.1016/j.amjsurg.2011.09.005

74. Kim S-J, Choi B-J, Lee SC (2018) Comparative analysis of outcomes after multiport and single-port laparoscopic colectomy in emergency situations: is single-port laparoscopic colectomy safe and feasible? Asian J Surg 41:20-29. https://doi.org/10.1016/j. asjsur.2016.07.008

75. Yu H, Shin JY (2016) Short-term outcomes following reducedport, single-port, and multi-port laparoscopic surgery for colon cancer: tailored laparoscopic approaches based on tumor size and nodal status. Int J Colorectal Dis 31:115-122. https://doi. org/10.1007/s00384-015-2399-z

76. Vestweber B, Vestweber K-H, Paul C, Rink AD (2016) Singleport laparoscopic resection for diverticular disease: experiences with more than 300 consecutive patients. Surg Endosc 30:50-58. https://doi.org/10.1007/s00464-015-4160-7

77. Yun J-A, Yun SH, Park YA, Huh JW, Cho YB, Kim HC, Lee WY (2016) Oncologic outcomes of single-incision laparoscopic surgery compared with conventional laparoscopy for colon cancer. Ann Surg 263:973-978. https://doi.org/10.1097/SLA.00000 00000001226

78. Keller DS, Flores-Gonzalez JR, Ibarra S, Haas EM (2016) Review of 500 single incision laparoscopic colorectal surgery cases-lessons learned. World J Gastroenterol 22:659. https:// doi.org/10.3748/wjg.v22.i2.659

79. Chouillard E, Alsabah S, Daher R, Younan A, Greco VJ, Chahine E, Abdullah B, Biagini J (2016) Single-incision laparoscopy could be better than standard laparoscopy in right colectomy for cancer. J Laparoendosc Adv Surg Tech 26:371-378. https://doi. org/10.1089/lap.2015.0231

80. Joshi H, Gosselink M, Adusumilli S, Hompes R, Cunningham C, Lindsey I, Jones O (2015) Single incision glove port laparoscopic colorectal cancer resection. Ann R Coll Surg Engl 97:204-207. https://doi.org/10.1308/003588414X14055925060677
81. Marks JH, Montenegro GA, Shields MV, Frenkel JL, Marks GJ (2015) Single-port laparoscopic colorectal surgery shows equivalent or better outcomes to standard laparoscopic surgery: results of a 190-patient, 7-criterion case-match study. Surg Endosc 29:1492-1499. https://doi.org/10.1007/s00464-014-3830-1

82. Kim CW, Cho MS, Baek SJ, Hur H, Min BS, Kang J, Baik SH, Lee KY, Kim NK (2015) Oncologic outcomes of single-incision versus conventional laparoscopic anterior resection for sigmoid colon cancer: a propensity-score matching analysis. Ann Surg Oncol 22:924-930. https://doi.org/10.1245/s10434-014-4039-1

83. Sangster W, Messaris E, Berg AS, Stewart DB (2015) Singlesite laparoscopic colorectal surgery provides similar clinical outcomes compared with standard laparoscopic surgery. Dis Colon Rectum 58:862-869. https://doi.org/10.1097/DCR.0000000000 000435

84. Khayat A, Maggiori L, Vicaut E, Ferron M, Panis Y (2015) Does single port improve results of laparoscopic colorectal surgery? a propensity score adjustment analysis. Surg Endosc 29:32163223. https://doi.org/10.1007/s00464-015-4063-7

85. D'Hondt M, Pottel H, Devriendt D, Van Rooy F, Vansteenkiste F, Van Ooteghem B, De Corte W (2014) SILS sigmoidectomy versus multiport laparoscopic sigmoidectomy for diverticulitis. J Soc Laparoendosc Surg 18:. https://doi.org/10.4293/ JSLS.2014.00319

86. Hiraki M, Takemasa I, Uemura M, Haraguchi N, Nishimura J, Hata T, Mizushima T, Yamamoto H, Doki Y, Mori M (2014) Evaluation of invasiveness in single-site laparoscopic colectomy, using "the PainVision ${ }^{\mathrm{TM}}$ system" for quantitative analysis of pain sensation. Surg Endosc 28:3216-3223. https://doi.org/10.1007/ s00464-014-3594-7

87. Sulu B, Gorgun E, Aytac E, Costedio MM, Kiran RP, Remzi FH (2014) Comparison of hospital costs for single-port and conventional laparoscopic colorectal resection: a case-matched study. Tech Coloproctol 18:835-839. https://doi.org/10.1007/s1015 1-014-1147-7

88. Takemasa I, Uemura M, Nishimura J, Mizushima T, Yamamoto H, Ikeda M, Sekimoto M, Doki Y, Mori M (2014) Feasibility of single-site laparoscopic colectomy with complete mesocolic excision for colon cancer: a prospective case-control comparison. Surg Endosc 28:1110-1118. https://doi.org/10.1007/s0046 4-013-3284-x

89. Park JW, Sohn DK, Park S, Park SC, Chang HJ, Son H-J, Oh JH (2013) Safety and efficacy of single-port colectomy for sigmoid colon cancer: a phase II clinical trial. J Laparoendosc Adv Surg Tech 23:745-750. https://doi.org/10.1089/lap.2013.0209

90. Pedraza R, Aminian A, Nieto J, Faraj C, Pickron TB, Haas EM (2013) Single-incision laparoscopic colectomy for cancer: shortterm outcomes and comparative analysis. Minim Invasive Surg 2013:1-5. https://doi.org/10.1155/2013/283438

91. Yun J-A, Yun SH, Park YA, Cho YB, Kim HC, Lee WY, Chun H-K (2013) Single-incision laparoscopic right colectomy compared with conventional laparoscopy for malignancy: assessment of perioperative and short-term oncologic outcomes. Surg Endosc 27:2122-2130. https://doi.org/10.1007/s0046 4-012-2722-5

92. Rosati CM, Boni L, Dionigi G, Cassinotti E, Giavarini L, David G, Rausei S, Rovera F, Dionigi R (2013) Single port versus standard laparoscopic right colectomies: results of a case-control retrospective study on one hundred patients. Int J Surg 11:S50 S53. https://doi.org/10.1016/S1743-9191(13)60016-3

93. Velthuis S, van den Boezem PB, Lips DJ, Prins HA, Cuesta MA, Sietses C (2012) Comparison of short-term surgical outcomes after single-incision laparoscopic versus multiport laparoscopic right colectomy: a two-center, prospective case-controlled 
study of 100 patients. Dig Surg 29:477-483. https://doi. org/10.1159/000346044

94. Keshava A, Young CJ, Richardson GL, De-Loyde K (2013) A historical comparison of single incision and conventional multiport laparoscopic right hemicolectomy. Color Dis 15:e618-e622. https://doi.org/10.1111/codi.12380

95. Vestweber B, Galetin T, Lammerting K, Paul C, Giehl J, Straub E, Kaldowski B, Alfes A, Vestweber K-H (2013) Single-incision laparoscopic surgery: outcomes from 224 colonic resections performed at a single center using SILS ${ }^{\mathrm{TM}}$. Surg Endosc 27:434442. https://doi.org/10.1007/s00464-012-2454-6

96. Mufty H, Hillewaere S, Appeltans B, Houben B (2012) Singleincision right hemicolectomy for malignancy: a feasible technique with standard laparoscopic instrumentation. Color Dis 14:e764-e770. https://doi.org/10.1111/j.1463-1318.2012.03175 .x

97. Park SJ, Lee KY, Kang BM, Choi SI, Lee SH (2013) Initial experience of single-port laparoscopic surgery for sigmoid colon cancer. World J Surg 37:652-656. https://doi.org/10.1007/s0026 8-012-1882-8

98. Lai CW, Edwards TJ, Clements DM, Coleman MG (2012) Single port laparoscopic right colonic resection using a "vesselfirst" approach. Color Dis 14:1138-1144. https://doi.org/10.111 1/j.1463-1318.2011.02898.x

99. Chew M-H, Chang M-H, Tan W-S, Wong MT-C, Tang C-L (2013) Conventional laparoscopic versus single-incision laparoscopic right hemicolectomy: a case cohort comparison of short-term outcomes in 144 consecutive cases. Surg Endosc 27:471-477. https://doi.org/10.1007/s00464-012-2460-8

100. Waters JA, Rapp BM, Guzman MJ, Jester AL, Selzer DJ, Robb BW, Johansen BJ, Tsai BM, Maun DC, George VV (2012) Single-port laparoscopic right hemicolectomy. Dis Colon Rectum 55:134-139. https://doi.org/10.1097/DCR.0b013e31823c0ae4

101. Champagne BJ, Papaconstantinou HT, Parmar SS, Nagle DA, Young-Fadok TM, Lee EC, Delaney CP (2012) Single-incision versus standard multiport laparoscopic colectomy. Ann Surg 255:66-69. https://doi.org/10.1097/SLA.0b013e3182378442

102. Kim S-J, Ryu G-O, Choi B-J, Kim J-G, Lee K-J, Lee SC, Oh S-T (2011) The short-term outcomes of conventional and single-port laparoscopic surgery for colorectal cancer. Ann Surg 254:933940. https://doi.org/10.1097/SLA.0b013e318237826b

103. Bulut O, Aslak KK, Levic K, Nielsen CB, Rømer E, Sørensen S, Christensen IJ, Nielsen HJ (2015) A randomized pilot study on single-port versus conventional laparoscopic rectal surgery: effects on postoperative pain and the stress response to surgery. Tech Coloproctol 19:11-22. https://doi.org/10.1007/s1015 1-014-1237-6

104. Bracale U, Melillo P, Lazzara F, Andreuccetti J, Stabilini C, Corcione F, Pignata G (2015) Single-access laparoscopic rectal resection versus the multiport technique. Surg Innov 22:46-53. https://doi.org/10.1177/1553350614529668

105. Kawahara H, Misawa T, Watanabe K, Hojo S, Ishida K, Akiba T, Yanaga K (2016) Feasibility of single-incision laparoscopic surgery plus one assist port for anterior resection. Anticancer Res 36:467-469

106. Kawamata F, Homma S, Minagawa N, Kawamura H, Takahashi N, Taketomi A (2014) Comparison of single-incision plus one additional port laparoscopy-assisted anterior resection with conventional laparoscopy-assisted anterior resection for rectal cancer. World J Surg 38:2716-2723. https://doi.org/10.1007/s0026 8-014-2642-8

107. Osborne AJ, Lim J, Gash KJ, Chaudhary B, Dixon AR (2013) Comparison of single-incision laparoscopic high anterior resection with standard laparoscopic high anterior resection. Color Dis 15:329-333. https://doi.org/10.1111/j.1463-1318.2012.03178.x
108. Tei M, Wakasugi M, Akamatsu H (2015) Comparison of shortterm surgical results of single-port and multi-port laparoscopic rectal resection for rectal cancer. Am J Surg 210:309-314. https ://doi.org/10.1016/j.amjsurg.2014.12.040

109. Zhang H, Ling Y, Cong J, Cui M, Liu D, Chen C (2016) Twoport laparoscopic anterior resection through a self-made glove device versus conventional laparoscopic anterior resection for rectal cancer: a comparison of short-term surgical results. World J Surg Oncol 14:275. https://doi.org/10.1186/s12957-016-1029-8

110. Sauerland S, Angrisani L, Belachew M, Chevallier JM, Favretti F, Finer N, Fingerhut A, Garcia Caballero M, Guisado Macias JA, Mittermair R, Morino M, Msika S, Rubino F, Tacchino R, Weiner R, Neugebauer EAM, European Association for Endoscopic Surgery (2005) Obesity surgery: Evidence-based guidelines of the European association for endoscopic surgery (EAES). Surg Endosc 19:200-221. https://doi.org/10.1007/s0046 4-004-9194-1

111. Morales-Conde S, del Agua IA, Moreno AB, Macías MS (2017) Postoperative pain after conventional laparoscopic versus single-port sleeve gastrectomy: a prospective, randomized, controlled pilot study. Surg Obes Relat Dis 13:608-613. https://doi. org/10.1016/j.soard.2016.11.012

112. Delgado S, Ibarzabal A, Adelsdorfer C, Adelsdorfer W, Corcelles R, Momblán D, Lacy AM (2012) Transumbilical single-port sleeve gastrectomy: initial experience and comparative study. Surg Endosc 26:1247-1253. https://doi.org/10.1007/s0046 4-011-2002-9

113. Lakdawala M, Agarwal A, Dhar S, Dhulla N, Remedios C, Bhasker AG (2015) Single-incision sleeve gastrectomy versus laparoscopic sleeve gastrectomy. A 2-year comparative analysis of 600 patients. Obes Surg 25:607-614. https://doi.org/10.1007/ s11695-014-1461-1

114. Saber AA, El-Ghazaly TH, Dewoolkar AV, Slayton SA (2010) Single-incision laparoscopic sleeve gastrectomy versus conventional multiport laparoscopic sleeve gastrectomy: technical considerations and strategic modifications. Surg Obes Relat Dis 6:658-664. https://doi.org/10.1016/j.soard.2010.03.004

115. Park K, Afthinos JN, Lee D, Koshy N, McGinty JJ, Teixeira JA (2012) Single port sleeve gastrectomy: strategic use of technology to re-establish fundamental tenets of multiport laparoscopy. Surg Obes Relat Dis 8:450-457. https://doi.org/10.1016/j.soard .2011 .06 .003

116. Gomberawalla A, Salamat A, Lutfi R (2014) Outcome analysis of single incision vs traditional multiport sleeve gastrectomy: a matched cohort study. Obes Surg 24:1870-1874. https://doi. org/10.1007/s11695-014-1312-0

117. Sucher R, Resch T, Mohr E, Perathoner A, Biebl M, Pratschke J, Mittermair R (2014) Single-incision laparoscopic sleeve gastrectomy versus multiport laparoscopic sleeve gastrectomy: analysis of 80 cases in a single center. J Laparoendosc Adv Surg Tech 24:83-88. https://doi.org/10.1089/lap.2013.0250

118. Muir KB, Rice WV (2016) Weight-loss outcomes of SPIDER $®$ sleeve gastrectomy at 6 months compared to traditional laparoscopic technique. Surg Endosc 30:2043-2048. https://doi. org/10.1007/s00464-015-4451-Z

119. Huang C-K, Lo C-H, Houng J-Y, Chen Y-S, Lee P-H (2012) Surgical results of single-incision transumbilical laparoscopic Roux-en-Y gastric bypass. Surg Obes Relat Dis 8:201-207. https ://doi.org/10.1016/j.soard.2010.12.007

120. Lee W-J, Chen J-C, Yao W-C, Taou J-J, Lee Y-C, Ser K-H (2012) Transumbilical 2-site laparoscopic Roux-en-Y gastric bypass: initial results of 100 cases and comparison with traditional laparoscopic technique. Surg Obes Relat Dis 8:208-213. https://doi. org/10.1016/j.soard.2010.12.004

121. Moreno-Sanz C, Morandeira-Rivas A, Sedano-Vizcaino C, Tenías-Burillo JM, Román-Ortíz C, de la Espada JBM 
(2015) Single-incision laparoscopic bariatric surgery: a systematic review. Surg Obes Relat Dis 11:248-257. https://doi. org/10.1016/j.soard.2013.11.013

122. Monclova JL, Targarona EM, Vidal P, Peraza Y, Garcia F, Otero CR, Pallares L, Balague C, Trias M (2013) Single incision versus reduced port splenectomy - searching for the best alternative to conventional laparoscopic splenectomy. Surg Endosc 27:895902. https://doi.org/10.1007/s00464-012-2530-y

123. Barbaros U, Aksakal N, Tukenmez M, Agcaoglu O, Bostan MS, Kilic B, Kalayci M, Dinccag A, Seven R, Mercan S (2015) Comparison of single port and three port laparoscopic splenectomy in patients with immune thrombocytopenic purpura: clinical comparative study. J Minim Access Surg 11:172-176. https:// doi.org/10.4103/0972-9941.159853

124. Han ES, You YK, Kim DG, Lee JS, Kim EY, Lee SH, Hong TH, $\mathrm{Na} \mathrm{GH}$ (2015) Clinical significance of single-port laparoscopic splenectomy: comparison of single-port and multiport laparoscopic procedure. Ann Surg Treat Res 89:55-60. https://doi. org/10.4174/astr.2015.89.2.55

125. Boone BA, Wagner P, Ganchuk E, Evans L, Evans S, Zeh HJ, Bartlett DL, Holtzman MP (2013) Single-incision laparoscopic splenectomy: preliminary experience in consecutive patients and comparison to standard laparoscopic splenectomy. Surg Endosc 27:587-592. https://doi.org/10.1007/s00464-012-2494-y

126. Choi KK, Kim MJ, Park H, Choi DW, Choi SH, Heo JS (2013) Single-incision laparoscopic splenectomy versus conventional multiport laparoscopic splenectomy. Surg Innov 20:40-45. https ://doi.org/10.1177/1553350612443898

127. Bayraktar B, Bayraktar O, Ozemir IA, Kizilkilic E, Ozturk E, Yigitbasi R (2015) Comparison of two minimal invasive techniques of splenectomy: standard laparoscopy versus transumbilical multiport single-site laparoscopy with conventional instruments. J Minim Access Surg 11:143-148. https://doi. org/10.4103/0972-9941.137756

128. Vidal O, Astudillo E, Valentini M, Ginestá C, Espert J, GracíaValdecasas J, Fernández-Cruz L (2014) Single-port laparoscopic left adrenalectomy (SILS): 3 years'experience of a single institution. Surg Laparosc Endosc Percutaneous Tech 24:440-443. https://doi.org/10.1097/SLE.0000000000000071

129. Wu S, Lai H, Zhao J, Chen J, Mo X, Zuo H, Lin Y (2016) Laparoendoscopic single-site adrenalectomy versus conventional laparoscopic adrenalectomy: an updated meta analysis. Urol J 13:2590-2598

130. Hu M, Zhao G, Wang F, Xu D, Liu R (2014) Single-port and multi-port laparoscopic left lateral liver sectionectomy for treating benign liver diseases: a prospective, randomized, controlled study. World J Surg 38:2668-2673. https://doi.org/10.1007/s0026 8-014-2610-3

131. Choi HJ, You YK, Na GH, Hong TH, Shetty GS, Kim DG (2012) Single-port laparoscopy-assisted donor right hepatectomy in living donor liver transplantation: sensible approach or unnecessary hindrance? Transplant Proc 44:347-352. https://doi. org/10.1016/j.transproceed.2012.01.018

132. Kim S-J, Kim K-H, An C-H, Kim J-S (2015) Innovative technique of needlescopic grasper-assisted single-incision laparoscopic common bile duct exploration: A comparative study. World J Gastroenterol 21:12857-12864. https://doi.org/10.3748/ wjg.v21.i45.12857

133. Aldrighetti L, Ratti F, Catena M, Pulitanò C, Ferla F, Cipriani F, Ferla G (2012) Laparoendoscopic single site (LESS) surgery for left-lateral hepatic sectionectomy as an alternative to traditional laparoscopy: case-matched analysis from a single center. Surg Endosc 26:2016-2022. https://doi.org/10.1007/s0046 4-012-2147-1

134. Wu S, Li Y, Tian Y, Li M (2014) Single-incision laparoscopic surgery versus standard laparoscopic surgery for unroofing of hepatic cysts. J Soc Laparoendosc Surg 18:246-251. https://doi. org/10.4293/108680813X13753907291512

135. Haugvik S-P, Røsok BI, Waage A, Mathisen Ø, Edwin B (2013) Single-incision versus conventional laparoscopic distal pancreatectomy: a single-institution case-control study. Langenbeck's Arch Surg 398:1091-1096. https://doi.org/10.1007/s0042 3-013-1133-y

136. Yao D, Wu S, Li Y, Chen Y, Yu X, Han J (2014) Transumbilical single-incision laparoscopic distal pancreatectomy: preliminary experience and comparison to conventional multiport laparoscopic surgery. BMC Surg 14:105. https://doi. org/10.1186/1471-2482-14-105

137. Han HJ, Yoon S-Y, Song T-J, Choi SB, Kim W-B, Choi S-Y, Park S-H (2014) Single-port laparoscopic distal pancreatectomy: initial experience. J Laparoendosc Adv Surg Tech 24:858-863. https://doi.org/10.1089/lap.2014.0151

138. Ryan CE, Ross SB, Sukharamwala PB, Sadowitz BD, Wood TW, Rosemurgy AS (2015) Distal pancreatectomy and splenectomy: a robotic or less approach. J Soc Laparoendosc Surg. https://doi. org/10.4293/JSLS.2014.00246

139. Sharp NE, Vassaur J, Buckley FP 3rd (2014) Single-site Nissen fundoplication versus laparoscopic Nissen fundoplication. J Soc Laparoendosc Surg. https://doi.org/10.4293/JSLS.2014.00202

140. Ross S, Roddenbery A, Luberice K, Paul H, Farrior T, Vice M, Patel K, Rosemurgy A (2013) Laparoendoscopic single site (LESS) vs. conventional laparoscopic fundoplication for GERD: is there a difference? Surg Endosc 27:538-547. https:// doi.org/10.1007/s00464-012-2476-0

141. Ahn S-H, Son S-Y, Jung DH, Park DJ, Kim H-H (2014) Pure single-port laparoscopic distal gastrectomy for early gastric cancer: comparative study with multi-port laparoscopic distal gastrectomy. J Am Coll Surg 219:933-943. https://doi. org/10.1016/j.jamcollsurg.2014.07.009

142. Kim SM, Ha MH, Seo JE, Kim JE, Choi MG, Sohn TS, Bae JM, Kim S, Lee JH (2016) Comparison of single-port and reduced-port totally laparoscopic distal gastrectomy for patients with early gastric cancer. Surg Endosc 30:3950-3957. https://doi.org/10.1007/s00464-015-4706-8

143. Omori T, Fujiwara Y, Moon J, Sugimura K, Miyata H, Masuzawa T, Kishi K, Miyoshi N, Tomokuni A, Akita H, Takahashi H, Kobayashi S, Yasui M, Ohue M, Yano M, Sakon M (2016) Comparison of single-incision and conventional multi-port laparoscopic distal gastrectomy with D2 lymph node dissection for gastric cancer: a propensity score-matched analysis. Ann Surg Oncol 23:817-824. https://doi.org/10.1245/s1043 4-016-5485-8

144. Choi BJ, Jeong WJ, Lee IK, Lee SC (2016) Single-port versus conventional three-port laparoscopic totally extraperitoneal inguinal hernia repair: a randomized controlled trial. Hernia 20:789-795. https://doi.org/10.1007/s10029-016-1499-1

145. Tran H, Turingan I, Tran K, Zajkowska M, Lam V, Hawthorne W (2014) Potential benefits of single-port compared to multiport laparoscopic inguinal herniorraphy: a prospective randomized controlled study. Hernia 18:731-744. https://doi.org/10.1007/ s10029-014-1261-5

146. Tsai Y-C, Ho C-H, Tai H-C, Chung S-D, Chueh S-C (2013) Laparoendoscopic single-site versus conventional laparoscopic total extraperitoneal hernia repair: a prospective randomized clinical trial. Surg Endosc 27:4684-4692. https://doi.org/10.1007/s0046 4-013-3116-z

147. Wijerathne S, Agarwal N, Ramzi A, Liem DH, Tan WB, Lomanto D (2016) Single-port versus conventional laparoscopic total extra-peritoneal inguinal hernia repair: a prospective, randomized, controlled clinical trial. Surg Endosc Other Interv Tech 30:1356-1363. https://doi.org/10.1007/s00464-015-4378-4 
148. Luo S, Wu S, Lai H, Mo X, Chen J (2017) Single-incision laparoscopic inguinal hernioplasty versus conventional laparoscopic inguinal hernioplasty. Surg Innov 24:171-182. https://doi. org/10.1177/1553350617690308

149. Białecki JT, Wieloch MM, Kołomecki K (2014) Single incision approach to totally extraperitoneal inguinal hernia repair. Videosurg Miniinvasive Tech 9:201. https://doi.org/10.5114/WIITM .2014 .41631

150. Lin C-D, Wu C-H, Liu Y-B, Tsai Y-C (2016) Feasibility and safety of laparoendoscopic single-site surgery of total extraperitoneal inguinal hernia repair after previous open groin hernia repair: a comparative study. Surg Endosc 30:2086-2089. https ://doi.org/10.1007/s00464-015-4461-x

151. Wakasugi M, Tei M, Anno K, Mikami T, Tsukada R, Koh M, Furukawa K, Suzuki Y, Masuzawa T, Kishi K, Tanemura M, Akamatsu H (2016) Single-incision totally extraperitoneal inguinal hernia repair as a teaching procedure: one center's experience of more than 300 procedures. Surg Today 46:1039-1044. https:// doi.org/10.1007/s00595-015-1273-5

152. Kim JH, Lee YS, Kim JJ, Park SM (2013) Single port laparoscopic totally extraperitoneal hernioplasty: a comparative study of short-term outcome with conventional laparoscopic totally extraperitoneal hernioplasty. World J Surg 37:746-751. https:// doi.org/10.1007/s00268-013-1925-9

153. Yang G, Lai E, Chan O, Tang C, Li M (2011) Single-incision transabdominal preperitoneal and totally extraperitoneal repair for inguinal hernia: early experience from a single center in Asia. Asian J Endosc Surg 4:166-170. https://doi.org/10.111 1/j.1758-5910.2011.00098.x

154. Dapri G, Gerard L, Paesmans M, Cadière G-B, Saussez S (2017) First 200 consecutive transumbilical single-incision laparoscopic TEPs. Hernia 21:29-35. https://doi.org/10.1007/s1002 9-016-1564-9

155. Buckley FP, @ bullet I, Vassaur H, Monsivais S, Sharp NE, Jupiter D, Watson R, Eckford J Comparison of outcomes for single-incision laparoscopic inguinal herniorrhaphy and traditional three-port laparoscopic herniorrhaphy at a single institution. Surg Endosc. https://doi.org/10.1007/s00464-013-3145-7

156. Ece I, Yilmaz H, Yormaz S, Sahin M (2017) Clinical outcomes of single incision laparoscopic surgery and conventional laparoscopic transabdominal preperitoneal inguinal hernia repair. J Minim Access Surg 13:37-41. https://doi.org/10.4103/0972-9941.181394

157. Grønvold LB, Spasojevic M, Nesgaard J-M, Ignjatovic D (2012) Single-incision laparoscopic versus conventional laparoscopic ventral hernia repair. Surg Laparosc Endosc Percutaneous Tech 22:354-357. https://doi.org/10.1097/SLE.0b013e318257cefc

158. Bucher P, Pugin F, Morel P (2011) Single-port access prosthetic repair for primary and incisional ventral hernia: toward less parietal trauma. Surg Endosc 25:1921-1925. https://doi.org/10.1007/s0046 4-010-1488-x

159. Dapri G, Bruyns J, Paesmans M, Himpens J, Cadière G-B (2013) Single-access laparoscopic primary and incisional prosthetic hernia repair: first 50 patients. Hernia 17:619-626. https://doi. org/10.1007/s10029-012-1025-Z

160. De Vogelaere K, Van De Winkel N, Simoens C, Delvaux G (2013) Intragastric SILS for GIST, a new challenge in oncologic surgery: first experiences. Anticancer Res 33:3359-3364

161. Na JU, Lee SI, Noh SM (2011) The single incision laparoscopic intragastric wedge resection of gastric submucosal tumor. J Gastric Cancer 11:225-229. https://doi.org/10.5230/jgc.2011.11.4.225

162. Choi CI, Lee SH, Hwang SH, Kim DH, Jeon TY, Kim DH, Kim GH, Park DY (2014) Single-incision intragastric resection for upper and mid gastric submucosal tumors: a case-series study. Ann Surg Treat Res 87:304. https://doi.org/10.4174/astr.2014.87.6.304

163. Morales-Conde S, Alarcón I, Ortiz-Moyano C, Barranco A, Padillo FJ, Socas M (2013) Intragastric endoscopic assisted single incision surgery for gastric leiomyoma of the esophagogastric junction. Case Rep Gastrointest Med 2013:391430. https://doi. org/10.1155/2013/391430

164. Bulian DR, Knuth J, Cerasani N, Sauerwald A, Lefering R, Heiss MM (2015) Transvaginal/transumbilical hybrid-NOTES-versus 3-trocar needlescopic cholecystectomy: short-term results of a randomized clinical trial. Ann Surg 261:451-458. https://doi. org/10.1097/SLA.0000000000000218

165. Kilian M, Raue W, Menenakos C, Wassersleben B, Hartmann J (2011) Transvaginal-hybrid vs. single-port-access vs. "conventional" laparoscopic cholecystectomy: a prospective observational study. Langenbeck's Arch Surg 396:709-715. https://doi. org/10.1007/s00423-011-0769-8

166. Navarra G, La Malfa G, Lazzara S, Ullo G, Currò G (2010) SILS and NOTES cholecystectomy: a tailored approach. J Laparoendosc Adv Surg Tech 20:511-514. https://doi.org/10.1089/lap.2010.0228

167. Bulian DR, Knuth J, Ströhlein MA, Sauerwald A, Heiss MM (2015) Transvaginale/transumbilikale Hybrid-NOTES-appendektomie. Der Chir 86:366-372. https://doi.org/10.1007/s00104-014-2774-2

168. Horgan S, Thompson K, Talamini M, Ferreres A, Jacobsen G, Spaun G, Cullen J, Swanstrom L (2011) Clinical experience with a multifunctional, flexible surgery system for endolumenal, singleport, and NOTES procedures. Surg Endosc 25:586-592. https://doi. org/10.1007/s00464-010-1225-5

169. Meillat H, de Chaisemartin C, Poizat F, Bories E, Fara R, Delpero JR, Lelong B (2017) Combined NOTES total mesorectal excision and single-incision laparoscopy principles for conservative proctectomy: a single-centre study. Tech Coloproctol 21:43-51. https ://doi.org/10.1007/s10151-016-1568-6

170. Kudsi OY, Castellanos A, Kaza S, McCarty J, Dickens E, Martin D, Tiesenga FM, Konstantinidis K, Hirides P, Mehendale S, Gonzalez A (2017) Cosmesis, patient satisfaction, and quality of life after da Vinci Single-Site cholecystectomy and multiport laparoscopic cholecystectomy: short-term results from a prospective, multicenter, randomized, controlled trial. Surg Endosc 31:3242-3250. https:// doi.org/10.1007/s00464-016-5353-4

171. Pietrabissa A, Pugliese L, Vinci A, Peri A, Tinozzi FP, Cavazzi E, Pellegrino E, Klersy C (2016) Short-term outcomes of single-site robotic cholecystectomy versus four-port laparoscopic cholecystectomy: a prospective, randomized, double-blind trial. Surg Endosc 30:3089-3097. https://doi.org/10.1007/s00464-015-4601-3

172. Balachandran B, Hufford TA, Mustafa T, Kochar K, Sulo S, Khorsand J (2017) A comparative study of outcomes between single-site robotic and multi-port laparoscopic cholecystectomy: an experience from a tertiary care center. World J Surg 41:1246-1253. https://doi.org/10.1007/s00268-016-3799-0

173. Gustafson M, Lescouflair T, Kimball R, Daoud I (2016) A comparison of robotic single-incision and traditional single-incision laparoscopic cholecystectomy. Surg Endosc 30:2276-2280. https ://doi.org/10.1007/s00464-015-4223-9

174. Buzad FA, Corne LM, Brown TC, Fagin RS, Hebert AE, Kaczmarek CA, Pack AN, Payne TN (2013) Single-site robotic cholecystectomy: efficiency and cost analysis. Int J Med Robot Comput Assist Surg 9:365-370. https://doi.org/10.1002/rcs.1507

175. Kroh M, El-Hayek K, Rosenblatt S, Chand B, Escobar P, Kaouk J, Chalikonda S (2011) First human surgery with a novel single-port robotic system: cholecystectomy using the da Vinci single-site platform. Surg Endosc 25:3566-3573. https://doi.org/10.1007/s0046 4-011-1759-1

176. Konstantinidis KM, Hirides P, Hirides S, Chrysocheris P, Georgiou M (2012) Cholecystectomy using a novel Single-Site ${ }^{\circledR}$ robotic platform: early experience from 45 consecutive cases. Surg Endosc 26:2687-2694. https://doi.org/10.1007/s00464-012-2227-2

177. Vidovszky TJ, Carr AD, Farinholt GN, Ho HS, Smith WH, Ali MR (2014) Single-site robotic cholecystectomy in a broadly inclusive 
patient population. Ann Surg 260:134-141. https://doi.org/10.1097/ SLA.0000000000000295

178. Morel P, Buchs NC, Iranmanesh P, Pugin F, Buehler L, Azagury DE, Jung M, Volonte F, Hagen ME (2014) Robotic single-site cholecystectomy. J Hepatobiliary Pancreat Sci 21:18-25. https://doi. org/10.1002/jhbp.36

179. Bibi S, Rahnemai-Azar AA, Coralic J, Bayoumi M, Khorsand J, Farkas DT, Prasad LM (2015) Single-site robotic cholecystectomy: the timeline of progress. World J Surg 39:2386-2391. https://doi. org/10.1007/s00268-015-3135-0

180. Lee H, Lee D-H, Kim H, Han Y, Kim S-W, Jang J-Y (2017) Singleincision robotic cholecystectomy: a special emphasis on utilization of transparent glove ports to overcome limitations of single-site port. Int J Med Robot Comput Assist Surg 13:e1789. https://doi. org/10.1002/rcs.1789

181. van der Linden YTK, Brenkman HJF, van der Horst S, van Grevenstein WMU, van Hillegersberg R, Ruurda JP (2016) Robotic single-port laparoscopic cholecystectomy is safe but faces technical challenges. J Laparoendosc Adv Surg Tech 26:857-861. https://doi. org/10.1089/lap.2016.0183

182. Ayloo S, Choudhury N (2014) Single-site robotic cholecystectomy. J Soc Laparoendosc Surg. https://doi.org/10.4293/ JSLS.2014.00266

Publisher's Note Springer Nature remains neutral with regard to jurisdictional claims in published maps and institutional affiliations.

\section{Affiliations}

Salvador Morales-Conde ${ }^{1} \cdot$ Andrea Peeters $^{2} \cdot$ Yannick M. Meyer $^{3}$ (D) Stavros A. Antoniou ${ }^{4} \cdot$ Isaías Alarcón del Agua ${ }^{1}$. Alberto Arezzo ${ }^{5}$. Simone Arolfo ${ }^{5}$. Amir Ben Yehuda ${ }^{6}$. Luigi Boni $^{7}$. Elisa Cassinotti ${ }^{7}$. Giovanni Dapri ${ }^{8}$. Tao Yang ${ }^{1}$. Sofie Fransen ${ }^{9}$. Antonello Forgione ${ }^{10}$. Shahab Hajibandeh ${ }^{11}$. Shahin Hajibandeh ${ }^{12}$. Michele Mazzola ${ }^{10}$. Marco Migliore ${ }^{5}$. Christof Mittermair ${ }^{13}$. Doris Mittermair ${ }^{13}$ - Antonio Morandeira-Rivas ${ }^{14} \cdot$ Carlos Moreno-Sanz $^{14}$. Andrea Morlacchi ${ }^{15}$. Eran Nizri ${ }^{16} \cdot$ Myrthe Nuijts $^{3}$. Jonas Raakow ${ }^{17}$. Francisco M. Sánchez-Margallo ${ }^{18}$. Juan A. Sánchez-Margallo ${ }^{18} \cdot$ Amir Szold $^{19} \cdot$ Helmut Weiss $^{13} \cdot$ Michael Weiss $^{13} \cdot$ Ricardo Zorron $^{15} \cdot$ Nicole D. Bouvy $^{3}$

1 Unit of Innovation in Minimally Invasive Sugery, Department of General and Digestive Surgery, University Hospital "Virgen del Rocio", Sevilla, Spain

2 Department of Clinical Epidemiology and Medical Technology Assessment, Maastricht University Medical Center, Maastricht, The Netherlands

3 Department of Surgery, Maastricht University Medical Center, Maastricht, The Netherlands

4 Colorectal Department, Royal Devon \& Exeter NHS Foundation Trust, Exeter, UK

5 Department of Surgical Sciences, University of Torino, Torino, Italy

6 Surgery division, Assaf Harofe medical center, Zeriffin, Israel

7 Department of Surgery, Fondazione IRCCS Ca' Granda Ospedale Maggiore Policlinico, University of Milan, Milan, Italy

8 Saint-Pierre University Hospital, Brussels, Belgium

9 Department of Surgery, Laurentius Ziekenhuis Roermond, Roermond, The Netherlands

10 Niguarda Cà Granda Hospital, Milan, Italy
11 Department of General Surgery, Royal Bolton Hospital, Bolton, UK

12 Department of General Surgery, Stepping Hill Hospital, Stockport, UK

13 SJOG Hospital - PMU Teaching Hospital, Salzburg, Austria

14 Department of Surgery, "La Mancha Centro" General Hospital, Alcázar de San Juan, Ciudad Real, Spain

15 Department of Surgery, University of Insubria, Varese, Italy

16 Surgery division, Tel Aviv Sourasky Medical Center, Tel Aviv, Israel

17 Center for Innovative Surgery- ZIC, Charité Universitätsmedizin, Chirurgische Klinik, Campus Charité Mitte/ Campus Virchow-Klinikum, Berlin, Germany

18 Jesús Usón Minimally Invasive Surgery Centre, Cáceres, Spain

19 Assia Medical Group, Tel Aviv, Israel 